\title{
Antibiotics in Aquaculture - Use, Abuse and Alternatives
}

\author{
Jaime Romero ${ }^{1}$, Carmen Gloria Feijoó ${ }^{2}$ and Paola Navarrete ${ }^{1}$ \\ ${ }^{1}$ Universidad de Chile, Biotechnology Laboratory, \\ Institute for Nutrition and Food Technology (INTA) \\ ${ }^{2}$ Universidad Andrés Bello, Laboratory of Developmental Biology, Santiago \\ Chile
}

\section{Introduction}

According to the UN Food and Agriculture Organization, aquaculture is growing more rapidly than all other animal food-production sectors (www.fao.org). Its contribution to global supplies of several species of fish, crustaceans and mollusks increased from $3.9 \%$ of total production by weight in 1970 to $33 \%$ in 2005. It has been estimated that fisheries and aquaculture supplied the world with about 110 million metric tons of food fish per year (FAO, State of World Fisheries and Aquaculture 2010.), providing a per capita supply of 16.7 $\mathrm{kg}$ (live weight equivalent). Of this supply, $47 \%$ is derived from aquaculture production. However, this production is hampered by unpredictable mortalities that may be due to negative interactions between fish and pathogenic bacteria. To solve this problem, farmers frequently use antibiotic compounds to treat bacterial diseases (Cabello 2006).

Aquaculture is becoming a more concentrated industry, with fewer, but much larger, farms. Infectious diseases are always a hazard and may cause significant stock losses and problems with animal welfare. Intensive aquaculture (shrimp and fish farming) has led to growing problems with bacterial diseases, the treatment of which now requires the intensive use of antimicrobials. Although various authors have emphasized the putative negative effects of using antimicrobial agents in fish farms (Alderman and Hastings, 1998; Cabello, 2006), few studies on antimicrobial resistance in the aquaculture industry have been performed in situ. (Fernández -Alarcón 2010, Miranda \& Zemelman 2002).

Because a wide variety of chemicals are currently used in aquaculture production, control measures have been introduced over the years. These include disinfectants (e.g., hydrogen peroxide and malachite green), antibiotics (e.g., sulfonamides and tetracyclines) and anthelmintic agents (e.g., pyrethroid insecticides and avermectins) (Rawn et al. 2009). However, disease control is an active research field, and alternatives to antibiotic treatments have been explored. The public health hazards related to antimicrobial use in aquaculture include the development and spread of antimicrobial-resistant bacteria and resistance genes and the presence of antimicrobial residues in aquaculture products and the environment.

The aim of this chapter is to present information about current knowledge regarding antibiotic use in aquaculture systems. This will include basic information, for example, 
mechanisms of action and resistance, the role of antibiotics in disease control and the putative negative impact of the use of antimicrobial agents in fish farms, and also some alternative strategies that could reduce the use of these chemicals.

\section{Use of antimicrobials in aquaculture}

\subsection{Controlling diseases using antibiotics}

Antimicrobial agents can be defined as substances that have the capacity to kill or inhibit the growth of microorganisms. After their formal discovery by Fleming in 1928, antibiotics have become essential drugs for human and animal health and welfare. Antibiotics can be derived from natural sources or have synthetic origins. Antibiotics should be safe (non-toxic) to the host, allowing their use as chemotherapeutic agents for the treatment of bacterial infectious diseases. In addition to their use in human medicine, antimicrobials are also used in food animals and aquaculture, and their use can be categorized as therapeutic, prophylactic or metaphylactic. Therapeutic use corresponds to the treatment of established infections. Metaphylaxis is a term used for group-medication procedures that aim to treat sick animals while also medicating others in the group to prevent disease. Prophylaxis means the preventative use of antimicrobials in either individuals or groups to prevent the development of infections. In aquaculture, antibiotics at therapeutic levels are frequently administered for short periods of time via the oral route to groups of fish that share tanks or cages. All drugs legally used in aquaculture must be approved by the government agency responsible for veterinary medicine, for example, the Food and Drug Administration (FDA) in the USA). For instance, in the USA the following antimicrobials are authorized for use in aquaculture: oxytetracycline, florfenicol, and Sulfadimethoxine/ormetoprim. These regulatory agencies may set rules for antibiotic use, including permissible routes of delivery, dose forms, withdrawal times, tolerances, and use by species, including dose rates and limitations. The most common route for the delivery of antibiotics to fish occurs through mixing the antibiotic with specially formulated feed. However, fish do not effectively metabolize antibiotics and will pass them largely unused back into the environment in feces. It has been estimated that 75 percent of the antibiotics fed to fish are excreted into the water (Burridge et al., 2010).

In most of the countries with an important aquaculture industry, government agencies exert some controlling actions. For example, in Norway the use of antimicrobials requires a veterinarian's prescription, and hence, their use is therapeutic. They are sold in pharmacies or in feed plants authorized by the Norwegian Medicines Agency. In Norway, it is mandatory to report the amount of antibiotics used and retain records of prescriptions.

Intensive fish farming has promoted the growth of several bacterial diseases, which has led to an increase in the use of antimicrobials (Defoirdt et al., 2011, 2007). Current levels of antimicrobial use in aquaculture worldwide are not easy to determine because different countries have different distribution and registration systems. Nevertheless, Burridge et al. (2010) reported that the amount of antibiotics and other compounds used in aquaculture differed significantly between countries. Defoirdt et al., (2011) previously estimated that approximately 500-600 metric tons of antibiotics were used in shrimp farm production in Thailand in 1994; he also emphasized the large variation between different countries, with antibiotic use ranging from $1 \mathrm{~g}$ per metric ton of production in Norway to $700 \mathrm{~g}$ per metric ton in Vietnam. 


\subsection{Antibiotics - Mechanisms of action}

Antimicrobial drugs may have different types of chemical structures, and they act on different parts of bacterial machinery. In general, antibiotics work by one of two mechanisms (Figure 1):

i. A bactericidal effect, i.e., the antibiotic generally kills the bacteria by interfering with either the formation of the bacterium's cell wall or its cell contents. Examples include penicillin, fluoroquinolones, and metronidazole.

ii. A bacteriostatic effect, i.e., the antibiotic stops bacteria from multiplying by interfering with bacterial protein production, DNA replication, or other aspects of bacterial cellular metabolism. Examples include tetracyclines, sulfonamides, chloramphenicol, and macrolides.

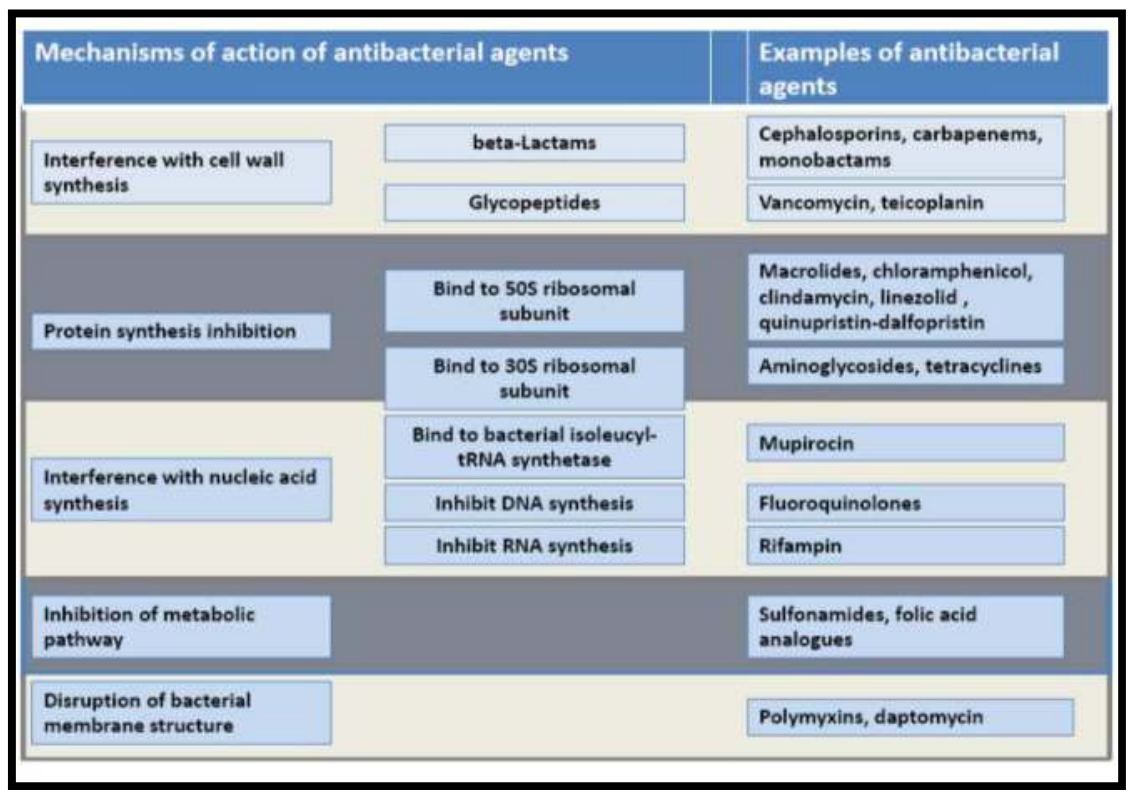

Fig. 1. Diagram showing the different mechanisms of action of antibiotics.

Some of the antibiotics that inhibit bacterial cell wall synthesis include Beta-lactams (penicillins, cephalosporins) and glycopeptides. Beta-Lactam drugs block the synthesis of the bacterial cell wall by interfering with the enzymes required for the synthesis of the peptidoglycan layer. In contrast, vancomycin and teicoplanin work by binding to the terminal D-alanine residues of growing peptidoglycan chains, thereby preventing the crosslinking steps required for stable cell wall synthesis.

Antibacterial drugs that work by inhibiting protein synthesis include macrolides, aminoglycosides, tetracyclines and chloramphenicol. These antibacterial drugs take advantage of the structural differences between bacterial and eukaryotic ribosomes to selectively inhibit bacterial growth. Macrolides, aminoglycosides, and tetracyclines bind to the $30 \mathrm{~S}$ subunit of the ribosome, whereas chloramphenicol binds to the $50 \mathrm{~S}$ subunit. 
Fluoroquinolones exert their antibacterial effects by disrupting DNA synthesis and causing lethal double-strand DNA breaks during DNA replication. For example, the bactericidal action of ciprofloxacin results from the inhibition of topoisomerase II (DNA gyrase) and topoisomerase IV (both Type II topoisomerases), which are required for bacterial DNA replication, transcription, repair, and recombination. Sulfonamides and trimethoprim (TMP) block the pathway for folic acid synthesis, which ultimately inhibits DNA synthesis. The common antibacterial drug combination of TMP, a folic acid analogue, plus sulfamethoxazole (SMX), a sulfonamide, inhibits 2 steps in the enzymatic pathway for bacterial folate synthesis. For example, sulfadimethoxine and ormetoprim are two different antibiotics compounded into one drug. Sulfadimethoxine is a long-acting sulfonamide and ormetoprim is a diaminopyrimidine structurally related to trimethoprim. These antibiotic drugs act in synergy because they block two sequential steps in bacterial folic acid synthesis, thus inhibiting bacterial thymidine synthesis. Sulfadimethoxine blocks the conversion of para-aminobenzoic acid to dihydrofolic acid by inhibiting the enzyme dihydrofolate synthetase. Ormetoprim blocks the conversion of dihydrofolic acid to tetrahydrofolic acid by inhibiting dihydrofolate reductase. The net effect is that of a potentiated sulfa whose action is not merely bacteriostatic but bactericidal.

Disruption of bacterial membrane structure may be a fifth, although less well characterized, mechanism of action. It is postulated that polymyxins accumulate in the bacterial cell membrane and exert their inhibitory effects by increasing bacterial membrane permeability. The cyclic lipopeptide daptomycin apparently inserts its lipid tail into the bacterial cell membrane, causing membrane depolarization and, eventually, the death of the bacterium (Carpenter \& Chambers, 2004).

\subsection{Resistance mechanisms and transference}

The use of antimicrobial drugs in aquaculture has particular differences from their use in terrestrial animals. In aquaculture, antimicrobials are regularly added to the feed, which is then placed in the water where the fish are kept. In some cases, antimicrobials may be added directly to the water. These procedures result in a selective pressure in the exposed environments (usually water). The use of antimicrobials in aquaculture may involve a broad environmental application that affects a wide variety of bacteria.

Several bacterial species may survive unfavorable conditions or environmental changes after selecting mutations that improve their fitness in the new conditions. Furthermore, bacteria take advantage of mobile genetic elements, such as plasmids and transposable elements. With these elements, bacteria can access a large pool of itinerant genes that move from one bacterial cell to another and can spread through bacterial populations. Some of these genes may provide the ability to resist antibiotic effects. Antibiotic resistance takes two forms:

i. Inherent or intrinsic resistance, i.e. the species is not normally susceptible to a particular drug. This may be due to the inability of the antibacterial agent to enter the bacteria cell and reach its target site, or a lack of affinity between the antibacterial and its target (site of action), or the absence of the target in the cell. It has been suggested that some species of bacteria are innately resistant to whole classes of antimicrobial agents. In such cases, all strains of that bacterial species are resistant to all members of the antibacterial classes. 
ii. Acquired resistance. This type of resistance represents the major cause for concern because of the transmissible nature of the resistance mechanisms. In this case, the bacterial species is normally susceptible to a particular drug, but some strains express drug resistance. Initially susceptible populations of bacteria become resistant to an antibacterial agent and proliferate and spread under the selective pressure induced by the use of that agent. Genes responsible for antibiotic resistance can be transferred between bacteria by three processes that involve lateral DNA transfer:

1. Transformation, i.e., bacteria acquire genes from the uptake of (foreign) DNA from the external environment;

2. Transduction, i.e., bacteria obtain genes through infection with viral DNA. This alternative has the potential to play an important role in resistance transference because of the high concentrations of viruses (bacteriophages) in aquatic habitats, seawater and the marine sediment.

3. Conjugation, i.e., bacteria gain genes by cell-to-cell mating. In this process, a plasmid is passed from one organism to another through a pilus. This may occur between members of same species or between bacteria from different genera or families. The spread of genes coding for antibiotic resistance is facilitated by mobile genetic elements called transposons, which can move from plasmids to the bacterial chromosome and in the reverse direction. A large family of discrete mobile genetic units called cassettes has been described; these elements act similarly to transposons. Cassettes may contain only one antibiotic resistance gene and a family of receptor elements called integrons that provide both the site into which gene cassettes are integrated and the enzyme responsible for gene movement (integrase). This enzyme can move these resistance cassettes in and out of the integron, thereby substantially increasing the horizontal mobility of antibiotic resistance genes and allowing bacteria to quickly adapt to environmental changes.

Several mechanisms of antimicrobial resistance are readily spread to a variety of bacterial genera. The microorganism may acquire genes encoding enzymes, such as beta-lactamases, which destroy beta-lactams (penicillins). Other antibiotic-inactivating enzymatic reactions include phosphorylation, adenylation, and acetylation. Recently, Kumarasamy et al., (2010) described the beta-lactamase NDM-1 as an example of how significant a single enzyme can be. This metallo-beta-lactamase is the cause of a dramatic and frightening rise in antibiotic resistance among enteric bacteria isolated from patients in India, Pakistan and the U.K. Bacteria may also acquire efflux pumps that excrete the antibacterial agent from the cell before it can reach its target site and exert its effect; these molecular pumps may energetically transfer antibiotics out of the cell. Bacteria may acquire several genes for a metabolic pathway that ultimately produces an altered bacterial cell wall that no longer contains the binding site for the antimicrobial agent, or bacteria may acquire mutations that limit the access of antimicrobial agents to the intracellular target site via the downregulation of porin genes. Ribosomes (RNA or proteins) may become altered due to mutations and chemical-physical changes that prevent antibiotic attachment. Therefore, normally susceptible bacterial populations may become resistant to antimicrobial agents through mutation and selection or by acquiring genetic information that encodes resistance from other bacteria.

Lateral DNA transfer mechanisms allow bacteria to acquire resistance to multiple classes of antibiotics. Bacteria with multidrug resistance (defined as resistance to $>3$ antibacterial drug classes) have become a cause for serious concern, particularly in healthcare institutions 
where they tend to occur most commonly. Similarly, an important consequence of the large amounts of antibiotics used for farm animals and fish in aquaculture is the selection of pathogenic bacteria resistant to multiple drugs. Multidrug resistance in bacteria may be generated by one of two mechanisms. First, these bacteria may accumulate multiple genes, each coding for resistance to a single drug, within a single cell. This accumulation typically occurs on resistance plasmids. Second, multidrug resistance may also occur through the increased expression of genes that code for multidrug efflux pumps that excrete a wide range of drugs.

\section{Antibiotic effects on host microbiota}

The intestinal tracts of healthy fish harbor a microbiota that has been investigated by several authors due to its assumed importance in digestion, nutrition and disease control (Navarrete et al. 2008). Studies in germ-free zebrafish have revealed that gut microbiota could be involved in important processes such as epithelial proliferation, the promotion of nutrient metabolism and innate immune responses (Bates et al. 2006). An important aspect of these results was the specificity of the host response, which depends on the bacterial species that colonize the digestive tract (Rawls et al. 2004). Possible modifications in gastrointestinal microbiota due to antibiotic treatment could alter this presumably beneficial host-microbiota relationship. Therefore, understanding how antibacterial compounds modify the gastrointestinal microbiota of farmed fish could help to improve the management of hatcheries to reduce antibiotic use and enhance the safety of farmed fish. However, few studies have focused on determining the effects of antibiotic treatment on the microbial ecology of the fish gut. In general, published studies have mainly focused on describing the frequency of antibiotic resistance during and after the use of antibiotics (Kerry et al. 1997), the susceptibility of fish pathogens isolated from fish and fish farms to antibiotics (Giraud et al., 2006; Kerry et al., 1997; Akinbowale et al., 2007) and molecular determinants of antibiotic resistance (Miranda et al., 2003; Miranda \& Zemelman, 2002). The impact of a specific antibiotic treatment on bacterial diversity will be reviewed in the next paragraphs. A special effort was made to describe the dominant bacterial components, especially the newly arising microbiota.

Navarrete et al (2008) evaluated the effects of oxytetracycline (OTC) treatment on bacterial populations present in the intestines of healthy juvenile salmon. Oxytetracycline was administered via medicated feed to Atlantic salmon held in experimental tanks and their intestinal microbiota were analyzed after culture. Isolates were analyzed by restriction fragment length polymorphism (RFLP) and sequencing of $16 \mathrm{~S}$ rDNA amplicons. Microbiota from the intestines of untreated fish were more diverse and their main components were Pseudomonas, Acinetobacter, Bacillus, Flavobacterium, Psycrobacter and Brevundimonas/ Caulobacter/Mycoplana. In contrast, the microbiota of the OTC treated group were characterized by less diversity and were only composed of Aeromonas, clustering with $A$. sobria and A. salmonicida. The frequency of resistant bacteria, defined as those capable of colony formation on TSA medium containing $30 \mu \mathrm{g} \mathrm{ml}^{-1}$ OTC, indicated that no resistant bacteria were detected $\left(<10^{2} \mathrm{CFU}\right.$ per gram) in the three tanks before OTC treatment. In treated fish, resistant bacteria accounted for $60 \%, 33 \%$ and $25 \%$ of isolates from the samples collected on day 11,21 , and 28 , respectively.

All resistant bacteria isolated from the treated group showed an identical RFLP pattern to that obtained for Aeromonas spp. 16S rDNA sequence analysis confirmed that these resistant 
phylotypes belonged to Aeromonas spp. The presence of class A family Tet tetracycline resistance genes $(\operatorname{tet} \mathrm{A}, \operatorname{tet} \mathrm{B}, \operatorname{tet} \mathrm{C}, \operatorname{tet} \mathrm{D}$, tet $\mathrm{E}$ and tet $\mathrm{H})$ was assessed by PCR and HaeIII digestion of amplicons (Jacobs \& Chenia, 2006; Schnabel \& Jones, 1999). The tetE determinant was detected most frequently among the isolates $(78 \%)$, while $22 \%$ of the isolates possessed tetD/H determinants.

Figure 2 shows a shift in the composition of the intestinal microbiota of the OTC-treated salmon, with several phylotypes disappearing and an Aeromonas population appearing (Figure 2). Bacteria belonging to this genus have been widely isolated from the gut microbiota of fish (Huber et al., 2004; Romero\& Navarrete, 2006) and are considered to be a normal bacterial component. However, some species of Aeromonas, including A. salmonicida, A. hydrophila, A. caviae and A. sobria, are also regarded as common pathogens of fish because they may cause furunculosis and hemorrhagic septicemia. More recently, Ringø et al., (2004) proposed that the digestive tract could represent a port of entry for invading bacteria, especially Aeromonas. Compared with the OTC-treated salmon, a more diverse bacterial composition was observed in the untreated salmon (Fig. 2B). Some authors have suggested that, to maintain a successful culture environment in an aquatic hatchery, it is necessary to maintain a diverse microbial community that includes innocuous and beneficial bacteria (Schulze et al. 2006). Therefore, the reduction in the diversity of the intestinal microbiota observed after OTC treatment could facilitate the proliferation or invasion of opportunistic microorganisms, as indicated by the rise of some phylotypes that became prevalent several weeks after treatment. Antibiotic treatment can eradicate susceptible microorganisms and promote opportunists that may occupy ecological niches previously unavailable to them. The occurrence of OTC-resistant bacteria, including Aeromonas species, in salmon farming has been demonstrated previously (Jacobs \& Chenia 2007). Mobile resistance determinants have also been detected in this genus (Miranda et al. 2003). The presence of bacteria harboring resistance determinants could be related to the widespread use of antibiotics in aquaculture (Cabello 2006). Some authors have even suggested that common components of the microbiota could disperse resistance genes via horizontal gene transfer because of the high density and proximity of resident bacteria in the gastrointestinal tract microenvironment (Navarrete et al. 2008).

In their study with rainbow trout, Austin and Al-Zahrani (1988) used erythromycin, oxolinic acid (OA), oxytetracycline (OTC), penicillin G and sulfafurazole to study the effects of antimicrobial compounds on aerobic heterotrophic gut microbiota. These authors observed that oxolinic acid, oxytetracycline and sulfafurazole, which are used to combat infections by gram-negative bacterial pathogens, caused an increase in bacterial numbers throughout the digestive tract, with maximal numbers in the lower intestine. Conversely, erythromycin and penicillin $\mathrm{G}$, which are used to treat some diseases caused by Gram-positive bacteria, caused a rapid reduction in bacterial numbers within the gastrointestinal tract. Overall, this evidence suggests that antibiotic treatment may change the composition of the intestinal microbiota of farmed fish, causing a reduction in bacterial diversity. This evidence supports the current concern that antibiotic treatment can eradicate microorganisms of the normal microbiota, facilitating the proliferation of opportunistic bacteria by depleting competition.

\section{Antibiotic effects on environmental bacteria}

The effects of fish farming on bacterial density, biomass, and community structure and the possible connections between these factors and antibiotic resistance have been investigated 


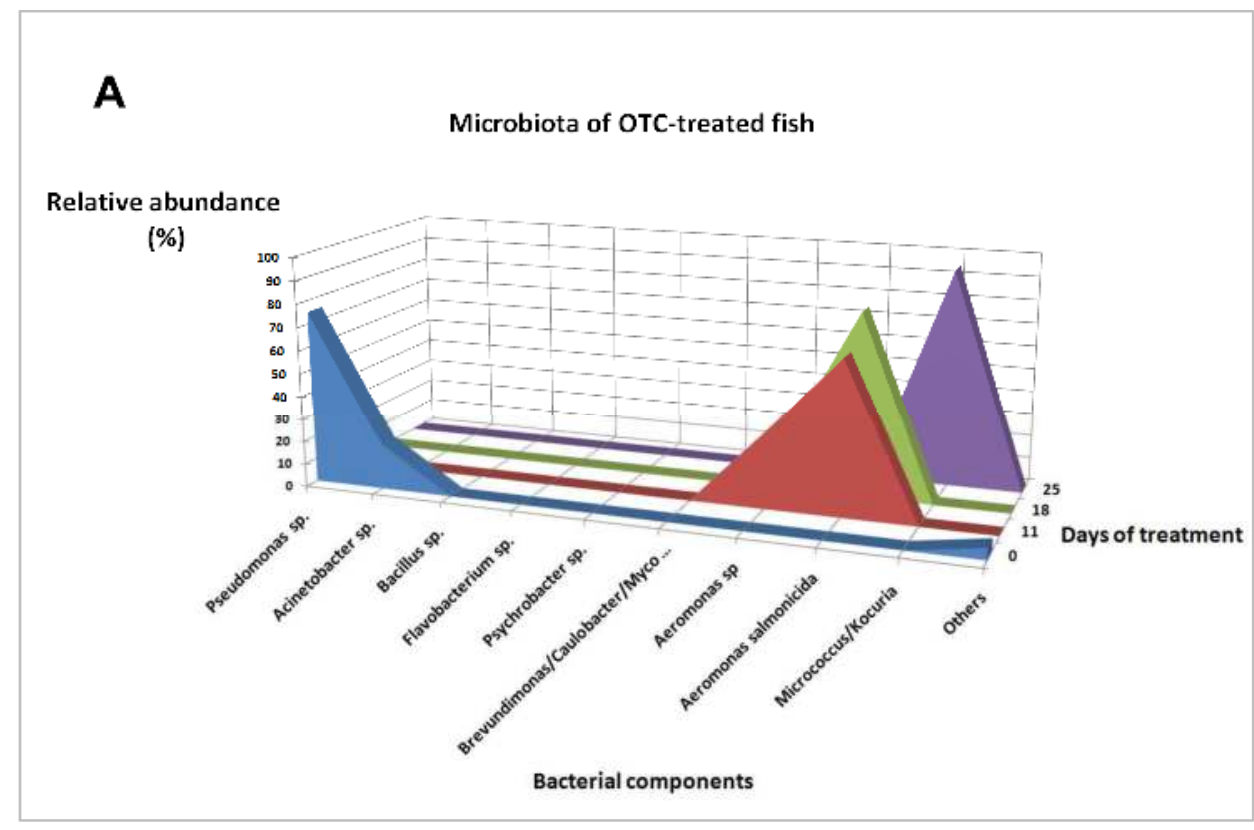

\section{B}

\section{Microbiota of untreated fish}

\section{Relative abundance}

(\%)

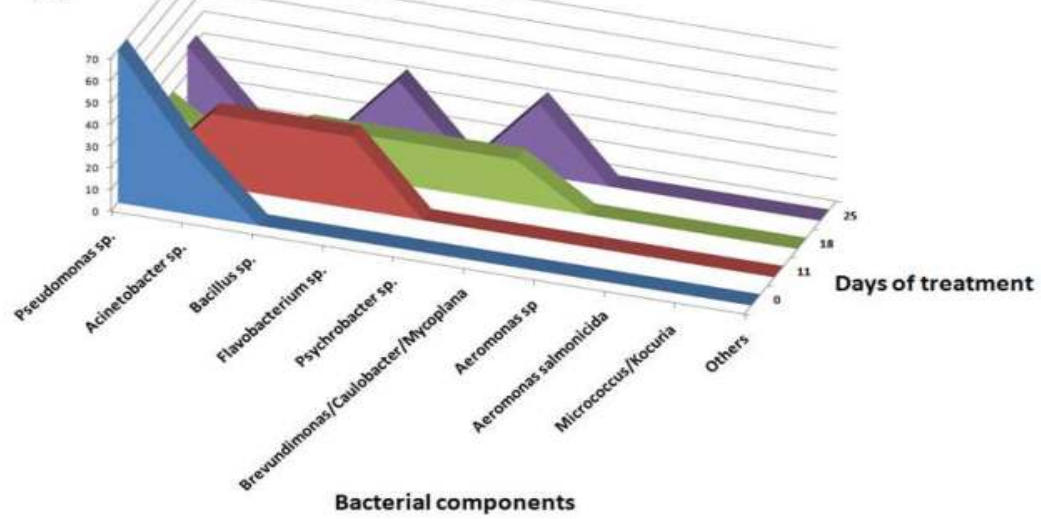

Fig. 2. Relative abundance of bacterial components in the gut microbiota. Bacteria were isolated from the intestines of untreated (control) and OTC-medicated salmon at different sampling times (day 0, i.e., one day before treatment, and days 11, 18 and 25 after treatment). A: OTC-medicated salmon, B: untreated salmon (control tanks). Adapted from Navarrete (2008). 
in several studies; however, the overall results are still controversial. When an antibiotic treatment begins (usually via medicated feed) the gut microbiota and environmental bacteria can come in contact with the antibiotics present in fish farm and hatchery wastes. In fact, treatment of salmonids with various antibiotics (including OTC) has been shown to result in significant increases in the proportion of the gut microbiota showing resistance to the administered antibiotics (Austin and Al-Zahrani 1988). The same is true for environmental bacteria coming into contact with wastes containing antibiotics such as OTC. The use of oxytetracycline in fish farming has been demonstrated to coincide with an increased frequency of oxytetracycline-resistant microorganisms (DePaola et al 1995). Miranda \& Zemelman (2002) also investigated the prevalence of oxytetracycline resistance in freshwater salmon farms, finding that the highest proportions of resistant bacteria were found in effluent samples (8-69\%), and these were significantly higher than those from the influent samples $(0-16 \%)$, which exhibited the lowest proportions of resistant bacteria. Clearly, these data suggest that the numbers of oxytetracycline-resistant bacteria are usually higher in fish farms undergoing antimicrobial therapy because susceptible microorganisms are inhibited, thus allowing colonization by resistant bacteria.

Oxytetracycline, one of the most commonly used antibiotics in fish farms and hatcheries, is very poorly absorbed through the intestinal tract of fish. It has to be administered at a high dosage rate of 100-150 mg per $\mathrm{kg}$ fish per day for 10-15 days. This treatment consequently causes the slow excretion of large amounts of this antibiotic, thus increasing the selective pressure which might lead to the selection of oxytetracycline-resistant bacteria in the gut (Austin and Al-Zahrani 1988; Navarrete 2008). Furthermore, it has been estimated that 70$80 \%$ of OTC is intact in the feces (Samuelsen, 2006; Ellingsen et al., 2002); although it appears to be degraded in seawater, it may persist in sediments. Following several OTC treatments, OTC levels in farm sediments reached $11 \mu \mathrm{g} / \mathrm{g}$ and the half-lives for OTC persistence were estimated to range from 9 to 415 days (Smith and Samuelsen 1996). In marine salmon farms, the proportion of OTC-resistant environmental bacteria can reach $25 \%$, compared with less than $5 \%$ in sites not affected by marine salmon farms.

In another report, Akinbowale et al (2007) used polymerase chain reaction (PCR) amplification to detect the genetic determinants responsible for tetracycline resistance (tet $\mathrm{R}$ genes) in oxytetracycline-resistant bacteria from aquaculture sources in Australia. Samples included different fish (skin, intestine), rearing tanks, and water from prawn farming. This study suggested that bacteria from aquaculture sources in Australia may contribute to the reservoir of resistance genes because one or more tet genes were detected in $75 \%$ of OTC resistant isolates. tetM (50\%) was the most common determinant, followed by tetE $(45 \%)$, tetA $(35 \%)$ and tetD $(15 \%)$. Furthermore, some OTC resistant isolates were able to transfer their R-plasmid to Escherichia coli recipients of chicken, pig and human origins in vitro. Therefore, most of the studies indicate that increased levels of antibiotic resistance can be expected to occur for as long as antibiotics are used in aquaculture. However, if the use of a given antibiotic in aquaculture is discontinued or if the frequency with which it is used is reduced, it appears likely that the advantage of possessing resistance to the antibiotic would disappear. Nevertheless, more recent observations could not confirm these initial speculations.

The available studies have focused on characterizing antibiotic-resistant bacterial isolates from aquaculture farms. However, it should be considered that almost $99 \%$ of 
environmental microbes are uncultivable (Amann et al., 1995); therefore, this approach has important limitations when attempting to determine the prevalence of resistance genes in the environment.

Using a culture-independent approach, Seyfried et al. (2010) assessed whether OTC use in aquaculture facilities increased the detection frequency of tet $\mathrm{R}$ genes relative to facilities with no recent OTC treatment. Using a conventional (qualitative) PCR strategy, these authors screened water and sediment from four noncommercial fish farms. tet $\mathrm{R}$ was detected at significantly higher frequencies in water from farms with recent OTC use compared with water from farms without recent OTC use. Although OTC use was associated with increased prevalence and diversity of tetR genes in water samples, it was not found to be correlated with the prevalence of tet $\mathrm{R}$ genes in sediment samples. Sediment samples from facilities with no recent OTC use had significantly higher frequencies of tetR gene detection than did samples from facilities with recent OTC use. These findings suggest that OTC treatment in aquaculture facilities and the farms themselves may be sources of tetR gene introduction to the environment.

A more comprehensive understanding of drug-resistance in aquaculture requires an unambiguous and quantitative analysis of resistance genes using a culture-independent approach. Tamminen et al. (2011) investigated the prevalence of tet resistance genes in sediments from aquaculture farms and their surroundings and analyzed the stability of these resistance genes over a period of several years. The prevalence of tet-genes was monitored by quantitative polymerase chain reaction (qPCR), and the total amounts of tetracycline and oxytetracycline in the samples were also measured. None of the farms were using tetracycline at the time of the sampling, and one of the farms had stopped all antibiotic use six years prior to the first sampling. Two of the farms were sampled over four successive summers, and two were sampled once. The authors reported greater copy numbers of tet $\mathrm{A}, t e t \mathrm{C}$, tet $\mathrm{H}$, and tet $\mathrm{M}$ at the farms compared to pristine sites. However, no resistance genes were found in samples collected $200 \mathrm{~m}$ from any of the farms. Furthermore, the analysis of tetracyclines indicated that none of the samples contained therapeutic concentrations at any of the sampling times, suggesting that the prevalence of tetracyclineresistance genes may be caused by the persistence of these genes in the absence of selection pressure. An increase in antibiotic-resistance genes in the absence of the antibiotic itself has also been attributed to co-selection with other antibiotics.

Miranda \& Rojas (2007) described the prevalence of florfenicol-resistant bacteria in a farm under florfenicol therapy two weeks before the date, designated LF1, and a farm with no recent history of antibacterial therapy, designated LF2. Samples from surface water, pellets, Salmo salar fingerlings and control and under-cage sediments were collected from each salmon farm. A low (<9\%) percentage of water and fingerling samples from both farms showed florfenicol resistance. However, $27 \%$ of sediment samples from LF1 showed florfenicol resistance (under-cage), and this was significantly higher than the prevalence in LF2 samples, which was < 1\%(under-cage). In a complementary study, Fernández-Alarcón et al. (2010) detected the florfenicol resistant gene in florfenicol-resistant isolates from these farms and other locations by using specific PCR amplification. The isolates carrying the floR gene showed a high incidence of multi-drug resistance, with all strains resistant to at least 5 of the following antibacterial drugs: ampicillin, cefotaxime, streptomycin, kanamycin, gentamicin, chloramphenicol, florfenicol, oxytetracycline, nalidixic acid, oxolinic acid, 
flumequine, furazolidone and trimethoprim-sulfamethoxazole. This observation indicated that a single antibiotic has the potential to co-select for a diversity of resistance genes.

Molecular approaches and massive sequencing methods could be important tools to elucidate the diversity of antibiotic-resistance genes present in the environment. The resistome concept has been used to describe the diversity of antibiotic resistance that exists naturally in a particular environment (Fernández-Alarcón 2010). However, the resistome of aquaculture environments has been poorly described. A comprehensive understanding of the influence of anthropogenic activities on the environment, for example, the long-term effects of antibiotic use on aquaculture facilities and their surroundings, will required more studies using molecular approaches. These approaches should allow the diversity of antibiotic resistance genes in an environment to be analyzed, even when no antibiotics are used and also permit the effects of antibiotics on bacterial populations to be evaluated. Recent studies have emphasized the observation that a single antibiotic has the potential to co-select for a diversity of resistances. To assess this potential risk, future studies should focus on the ability of different antibiotics used in aquatic environments to co-select for multiple resistances.

\section{Selection of fish pathogens resistant to antibiotics}

The major concerns with treating fish with antibiotics are the potential impact of antimicrobials on the aquatic environment, both marine and fresh water, and the wider theoretical risks associated with the development of antimicrobial resistance by fish pathogens. The spread of antimicrobial resistance due to exposure to antimicrobial agents is well documented in both human and veterinary medicine. It is also well documented that fish pathogens and other aquatic bacteria can develop resistance as a result of antimicrobial exposure. Examples include Aeromonas salmonicida, Aeromonas hydrophila, Edwardsiella tarda, Yersinia ruckeri, Photobacterium damselae and Vibrio anguillarum.

Aeromonas salmonicida, which causes disease in fish from temperate and colder areas, easily develops resistance when exposed to antimicrobials. Sulfonamide was used in the 1950 to control this pathogen; however, resistance to this drug emerged with a prevalence $>75 \%$. More recently, multiresistant Aeromonas salmonicida isolates have been described in various parts of the world, and transferable resistance plasmids are commonly detected in these strains. Similar findings have been reported in other countries for other bacterial fish pathogens following the use of antibiotics to control diseases in cultured salmonids. When antibiotic resistance occurs, the effectiveness of the antibiotics for treating fish diseases is compromised.

Currently, antibiotics are only partially effective due to the emergence of resistant bacteria; therapeutic treatments may have limited success at controlling infectious bacterial diseases. For instance, Karunasagar et al. (1994) reported mass mortality in Penaeus monodon larvae caused by Vibrio harveyi strains with multiple resistances to cotrimoxazole, chloramphenicol, erythromycin and streptomycin. Genetic determinants of antibiotic resistance that have been described in aquaculture environments are regularly located on mobile genetic elements. Indeed, resistance genes have been found located on transferable plasmids and integrons in pathogenic bacteria such as Aeromonas spp., Edwardsiella spp. and Vibrio spp. (Defoirdt et al 2011). 
In summary, the high proportions of antibiotic-resistant bacteria that persist in sediments and farm environments may provide a threat to fish farms because they can act as sources of antibiotic-resistance genes for fish pathogens in the vicinity of the farms. Because resistant bacteria may transfer their resistance elements to bacterial pathogens, the implementation of efficient strategies to contain and manage resistance-gene emergence and spread is critical. Inefficiencies in the antibiotic treatment of fish illnesses may lead to significant economic losses in the future.

\section{Antibiotics and their effects on fish stress responses}

The use of antimicrobial drugs in aquaculture has well-known positive effects on the control of bacterial infections; however, several side effects that affect both the fish and the environment are associated with excessive use. If one takes into account that 70 to $80 \%$ of the antibiotics administered to fish as medicated pelleted feed are released into the aquatic environment via urinary and fecal excretion and/or as unused medicated food (Martinsen \& Horsberg, 1995; Smith \& Samuelsen, 1996; Samuelsen, 2006), it is not hard to imagine the extent to which antibiotics can affect the aquatic habitat. The effects of antibiotics on the environment are mainly due to the overuse of these drugs by the aquaculture industry and the presence of drug residues in fish products (Saglam \& Yonar, 2009). Unfortunately, there are only a few studies that analyze the side effects of antibiotic use on fish themselves. There is evidence that some antibiotics can induce nephrotoxicity (Hentschel et al., 2005), but the most well documented side effect is immunomodulation (Rijkers et al., 1981; Grondel et al., 1985; Wishkovsky et al., 1987; Tafalla et al., 2002).

In the case of nephrotoxicity, a study conducted by the Bonventre group (Hentschel et al., 2005) determined that, as in rats and humans, gentamicin, an aminoglycoside antibiotic, induces acute renal failure in fish. Their results showed that gentamicin induced pericardial edema in a time- and dose-dependent manner, which resulted in the fish being unable to maintain fluid homeostasis. In addition, a histological analysis of treated larvae pronephros demonstrated the existence of lysosomal phospholipidosis, flattening of the brush border, accumulation of debris in the tubular lumen, and tubular and glomerular distention. Moreover, they observed peritubular accumulation of leukocytes with occasional infiltration into the glomerulus in the medicated larvae, a typical feature of human acute renal failure.

Immunomodulation is a consequence of a change in the quantity and/or function of the cells or molecules involved in the immune responses. In addition to natural immunoregulatory mechanisms, a number of drugs and environmental chemicals are known to induce alterations in the immune system. It is important to remember that the immunomodulatory effects of the antibiotics used in aquaculture are variable and depend on the drug, the protocol used in the analysis, and the fish species. At present, a few reports have been published that describe the effects of oxytetracycline, florfenicol and, to a lesser extent, oxolinic acid on the fish immune system. There is evidence suggesting that oxytetracycline can suppress immune functions in carp, rainbow trout, turbot and Atlantic cod. The first studies were carried out in vitro and showed that oxytetracycline suppressed mitogenic and allogenic leukocyte responses in fish and that low concentrations of this antibiotic delayed the mitogenic response, but did not reduce it (Grondel et al., 1985). In vitro experiments in rainbow trout and in turbot demonstrated that oxytetracycline also suppressed macrophage phagocytic capacity in these two species (Wishkovsky et al., 1987; 
Tafalla et al., 1999). Moreover, in turbot, both respiratory burst activity and phagocytosis were significantly suppressed by incubation with oxytetracycline in vitro. However, phagocytosis seems to be more sensitive to oxytetracycline because it was inhibited by all the doses used (Tafalla et al., 1999). Unexpectedly, these two macrophage functions were not suppressed when the effects of oxytetracycline were examined in vivo by the same authors, probably as a result of the low antibiotic levels present in the head kidney due to poor absorption rates. In many cases, contradictory results have been reported depending on the fish species and especially the antibiotic dose and the route of administration, making it very difficult to compare results from different studies. One study showing a discrepancy between different administration routes was conducted by Rijkers and collaborators. They analyzed the in vivo effects of oxytetracycline, administered either orally in the feed or by intraperitoneal injection, on immune function in the carp. To determinate the effects on cellular immunity, allogeneic scale transplantation was carried out. In the case of oral administration, they determined that there was no effect on the median survival time (MST) of the scales. However, the injected fish showed significantly prolonged MST, 11-20 days compared to control fish with 8.5 days. Thus, cellular immunity was not affected by oral administration of oxytetracycline, but injections did have a dramatic immunosuppressive effect. To study the effect of oxytetracycline on humoral immunity, animals were injected with red blood cells from rabbits and sheep, and the number of rosette-forming cells in the spleen was determined. Regardless of the route of administration, the serum immunoglobulin levels were drastically decreased by oxytetracycline (Rijkers et al., 1981). Lundên and collaborators studied the effects of several antibiotics, including oxolinic acid, oxytetracycline, florfenicol and trimethoprim in combination with sulfadiazine, on different aspects of immune function in rainbow trout (Oncorhynchus mykiss) (Lunden et al., 1998; Lunden et al., 1999; Lunden \& Bylund, 2002). The results for oxolinic acid and oxytetracycline, both in vitro and in vivo, indicated that these antibiotics suppressed the mitogenic response of head kidney lymphoid cells. Moreover, the suppression of the response was stronger in T cells than in B cells.

Reports concerning florfenicol are even more controversial, but there is a consensus that its effects appear to be less pronounced than those demonstrated for oxytetracycline and oxolinic acid. Lundên and collaborators analyzed immune responses after vaccination with simultaneous oral antibiotic treatment in rainbow trout (Lunden et al., 1999). They found that florfenicol did not have any significant effect on antibody production or on circulating leukocyte levels. They only detected a decrease in the number of phagocytic cells 5-6 weeks after vaccination and a slightly reduction in fish survival after challenge with A. salmonicida. The same research group used a different approach to show that oxolinic acid and florfenicol suppressed the respiratory burst of phagocytic cells in rainbow trout both in vitro and in vivo (Lunden \& Bylund., 2002). Again, contradictory results were obtained due to the use of different protocols to analyze the same biological question. Caipang and collaborators (Caipang et al., 2009) demonstrated that florfenicol and oxolinic acid were able to modulate different compounds of the immune system in another fish species, namely Atlantic cod. They found that, at therapeutic concentrations, the activity of alkaline phosphatase, but not that of myeloperoxidase, was altered. Transcript levels of the pro-inflammatory cytokines IL-1 $\beta$ and IL- 8 were upregulated, as was the bactericidal permeability-increasing protein (BPI); the expression of g-type lysozyme was downregulated. In the case of the oxidative stress-related genes catalase and phospholipid hydroperoxide glutathione peroxidase (GSH- 
Px), they observed differential effects of florfenicol and oxolinic acid on the expression levels (Caipang et al., 2009).

The antimicrobial effects on the immune system described above were detected using assays in which the drug was administered orally or injected into the fish; these studies did not examine the effects caused by exposure to antibiotics that remain in the water column and/or in the sediment. It is common to dose farmed fish with antibiotics in their food to protect against disease and, as fish pens are typically located in rivers or lakes, the toxic feces, uneaten food pellets, dead fish, and antibiotic residues are distributed over the entire ecosystem. This is an important point because, as active compounds, antibiotics must be considered potential environmental micropollutants and thus a source of artificial environmental stress for fish. Furthermore, in addition to the presence of the antibiotic itself, the existence of its degradation products is also a cause for concern. Unfortunately, no studies of these problems have been published, and only limited information is available regarding the presence, or absence, of antibiotics (mainly oxytetracycline, florfenicol and oxolinic acid) in the sediment around fish farm nets in a few countries (Carson et al., 2002; Lalumera et al., 2004; Pouliquen et al., 2007). The use of drugs in aquaculture has different legal constraints in each country, and supervision of compliance with regulations also varies between different countries. Likewise, companies have different ways of working, depending on the country where they are. Some information can be obtained from the industry websites. An example of this is Marine Harvest, which is one of the most important salmon farming businesses, which is headquartered in Norway and has subsidiaries in several countries. In the recent Sustainability reports submitted by Marine Harvest (http://marineharvest.com/Global/Sustainability/UoP\%20final\%20LO.pdf), they stated the amount of antibiotics used in all countries where the company conducts salmonid farming. In spite of important disparities in the amount of antibiotic used in the different countries, a global tendency to reduce antibiotic to disease control can be observed.

It is imperative to investigate how long different antibiotics can persist in the water and whether this time period is sufficient to alter the wellbeing of the farmed fish. This invaluable information will help determine the conditions that promote fish health and survival. Pouliquen and collaborators (Pouliquen et al., 2009) have quantified the amount of oxolinic acid, flumequine, oxytetracycline, and florfenicol present in four fish farms in France. They only detected florfenicol in one sediment sample, possibly due to the limited use of this antibiotic, which is mainly used in winter treatment and restricted to fry or young trout. In the case of oxytetracycline, they found relatively few sediment samples were contaminated with this antibiotic, presumably due to its weak stability. OTC undergoes photolysis and hydrolysis in the water column and in the first few centimeters of each layer of sediment. However, oxytetracycline can still be detected in sediments under aerobic conditions after 30 days. Compared with florfenicol and oxytetracycline, oxolinic acid and flumequine were more frequently detected due to their greater consumption and persistence. It is important to note that this work was done in a country with very low levels of fish farming; the situation is very different in countries like Ireland, Canada, Chile and Norway, where aquaculture is a highly developed industry. The difference is apparent, even in the case of Norway, which uses fewer antibiotics than the other three countries. Samuelsen and collaborators determined the amount of oxytetracycline in the sediment of three selected cages at a fish farm in Norway over a period of 18 months after 10 days of medication with the antibiotic. Most of the oxytetracycline disappeared during the first 
weeks, but it persisted in the sediment at lower concentrations for quite some time after the initial medication. The half-life of oxytetracycline in the sediment was measured as 125, 144 and 87 days under each of the cages. At the end of the treatment protocol, all three sediments contained 100\% oxytetracycline-resistant bacteria (Samuelsen et al., 1992). The next step will be to analyze whether there are any physiological changes in fish that live in pens where antibiotic residues were found in the surrounding sediment.

Due to the absence of any published report on the effects of chronic exposure to any antibiotic on stress levels and/or immune function, we decided to investigate the effect of two of the most commonly used antibiotics, namely oxytetracycline and florfenicol, on zebrafish (Danio rerio). This teleost fish has several advantages as a model organism, including an especially well-studied biology, rapid development, ease of handling, and more importantly, the ability to perform in vivo analyses. Due to its versatility, the zebrafish has become one of the preferred animal models for performing ecotoxicology and toxicology research (Froehlicher et al., 2009). We took advantage of the existence of a stress-responsive transgenic line, Hsp70::GFP, that expresses green fluorescent protein when the larvae are exposed to stressors like extreme temperature and heavy metals. The primary response of fish to stress involves the activation of the hypothalamic-pituitary-interrenal axis. This activation leads to increased levels of adrenocorticotropic hormone and the glucocorticoid hormone, cortisol, (Barton, 2002). Moreover, plasma cortisol is used as a routine indicator of the magnitude and duration of the stress response. Previous research in rainbow trout has demonstrated that Hsp70 and the glucocortocoid receptor (GR) maintain a balanced sequential pro-inflammatory and anti-inflammatory cytokine expression profile that is required for effective immune responses. Heat stress and cortisol treatment have also been shown to stimulate the association of Hsp70 with the glucocorticoid receptor (Stolte et al., 2009), indicating that Hsp70 is a good molecular marker to address for both cellular and molecular stress. To determinate whether the selected antibiotics could modulate stress levels in vivo, we developed an assay in which we incubated zebrafish larvae for 48 hours in the highest sublethal concentration of each antibiotic. In the case of oxytetracycline, we used $750 \mathrm{ppm}$ because this concentration is not lethal nor does it produce obvious phenotypic changes during 4 days of larvae incubation. Next, we analyzed whether chronic exposure to $750 \mathrm{ppm}$ of oxytetracycline could activate the Hsp70 promoter. We incubated HSP70::GFP transgenic larvae for $48 \mathrm{hrs}$ in $750 \mathrm{ppm}$ oxytetracycline per triplicate and analyzed the resulting fluorescence. At 6 hours post treatment (hpt), we found that there was no obvious difference between the control and experimental larvae; the only GFP detected was the basal expression in the lens. At $12 \mathrm{hpt}$, fluorescence in the trunk and tail was limited; only a few muscle fibers expressed GFP. After $24 \mathrm{hrs}$ of treatment the GFP expression became more ubiquitous, but it was not until $48 \mathrm{hpt}$ when strong fluorescence was detected (Figure 3) (Feijoo, unpublished data). These results indicate that the activation of the Hsp70 promoter is gradual, and the full response is obtained after 48 hours of treatment. Prolonged exposure to oxytetracycline strongly upregulated the stress levels of the zebrafish and, thus, may alter immune responses and the ability to cope with pathogen infections. Further experiments are needed to corroborate the effect of oxytetracycline-triggered stress on the immune response, such as determining the level of pro-inflammatory cytokines, including IL-1, IL-8, and IL-6, and chronic inflammation markers such as iNos and the respiratory burst. Nonetheless, previous studies supported our hypothesis because they indicated that the immune response is inhibited or depressed as a consequence of stress (Ortuño et al., 2001). Moreover, 


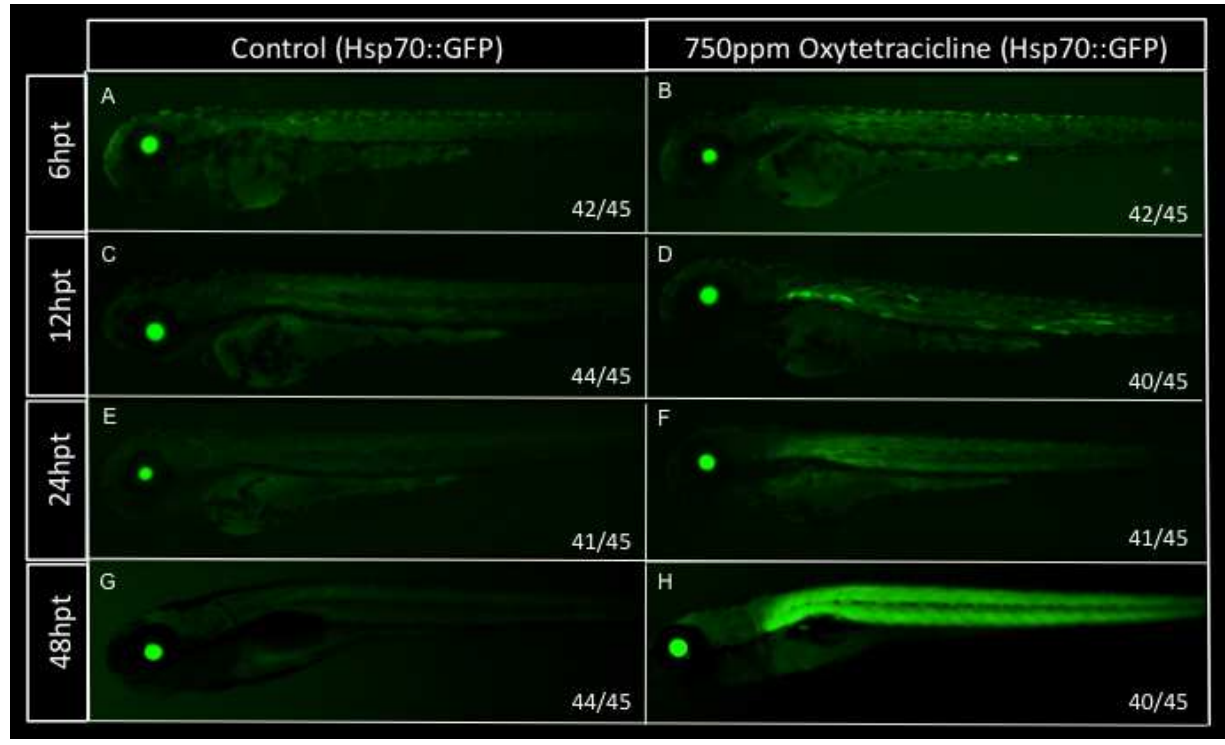

Fig. 3. Oxytetracycline effects on stress levels. Lateral view of Hsp70::GFP transgenic larva incubated in 750 ppm oxytetracycline or control medium for $6 \mathrm{hrs}$ (A, B), 12 hrs (C, D), 24 hrs (E, F) and 48 hrs $(\mathrm{G}, \mathrm{H})$. hpt, hours post treatment.

chronic elevation of plasma cortisol levels in fish was shown to result in a dose-dependent increase in mortality due to common bacterial and fungal diseases (Pickering \& Pottinger, 1989).

\section{Antibiotics and public health}

The use of antibiotics in aquaculture depends on the local regulations, which vary widely between different countries. The emerging view that antibiotics should be used with more care has prompted more strict regulations on the use of antibiotics in aquaculture and on the presence of antibiotic residues in aquaculture products. In some countries, regulations on the use of antibiotics are strict, and only a few antibiotics are licensed for use in aquaculture. However, a large proportion of global aquaculture production takes place in countries that have permissive regulations. Furthermore, many governments have set obligatory Maximum Residue Levels (MRLs) for aquaculture products. The public health risk associated with antimicrobial residues depends on the quantity of the antimicrobial encountered or consumed, i.e. the exposure. In a FAO/OIE/WHO consultation on scientific issues related to non-human usage of antimicrobials held in Geneva in December, 2003, it was concluded that antimicrobial residues in foods represent a significantly less important human health risk than the risk related to antimicrobial-resistant bacteria in food.

The presence of antibiotic-resistant bacteria in foods of animal origin is a potential health threat because resistance can be transferred among bacteria, and antibiotic-resistant pathogens may not respond to antibiotic treatments. In a microbiological study of market products, Duran \& Marshall (2005) examined several brands of ready-to-eat shrimp that 
were obtained from grocery stores. A total of 1,564 isolates corresponding to 162 bacterial species were recovered while screening for resistance to the following 10 antibiotics: ampicillin, ceftriaxone, chloramphenicol, clindamycin, erythromycin, nalidixic acid, streptomycin, tetracycline, trimethoprim, and vancomycin. These authors reported that $42 \%$ of the isolates and $81 \%$ of the species showed resistance to antibiotics. Several human pathogens were observed among the resistant isolates, including Escherichia coli, Salmonella, Shigella and Vibrio spp.

Antimicrobial-resistant bacteria in aquaculture present a risk to public health. The appearance of acquired resistance in fish pathogens and other aquatic bacteria means that such resistant bacteria can act as a reservoir of resistance genes from which genes can be further disseminated and may ultimately end up in human pathogens. Plasmid-borne resistance genes have been transferred by conjugation from the fish pathogen $A$. salmonicida to Escherichia coli, a bacterium of human origin, some strains of which are pathogenic for humans. In other examples, plasmid-borne drug resistance genes have also been transferred from the fish pathogen Vibrio anguillarum to the causative bacterium of cholera in humans, Vibrio cholera (Nakajima et al. 1983).

It is important to consider that most antibiotics used for treating infections are produced by environmental microorganisms, meaning that the genes for antibiotic resistance must also have emerged in non-clinical/artificial habitats (Martínez 2008). A better understanding of the ecological role of antibiotics and antibiotic resistance in natural environments may eventually help to predict and counteract the emergence and evolution of resistance.

\section{Alternative treatments: Probiotics, essential oils and phage therapy}

The rise in bacterial antibiotic resistance and antibiotic residues has become global concerns, and there is a need to develop alternative therapies for bacterial pathogens in animal production, especially in aquaculture. Vaccination is an ideal method for preventing infectious diseases, but it is not a treatment for existing infections, and commercially available vaccines are still very limited in the aquaculture field. Several alternatives to the use of antibiotics have been used successfully in aquaculture. The use of innocuous microorganisms to avoid bacterial infection in aquatic organisms has been tested in aquaculture. Here, we include a brief review of the use of probiotics in aquaculture and discuss some of the suggested mechanisms by which they might control aquatic pathogens. Another source of alternative treatments is essential oils, which are natural components from plants that are generally recognized as safe substances (GRAS). Due to their antimicrobial properties, these oils may constitute alternative prophylactic and therapeutic agents in aquaculture. Furthermore, phage therapy has gained much attention for its advantages in preventing and controlling pathogen infections; since 1999, phages have been used successfully in aquaculture facilities.

\subsection{The use of probiotics as an alternative to antibiotics in aquaculture}

Elie Metchnikoff was the first to report the beneficial effects of fermented milk products containing microorganisms; however Kollath was the first to suggest the term "probiotics" to designate organic or inorganic substances that are essential to the healthy development of life (Desriac et al., 2010). The definition of probiotics has changed many times, and The 
International Scientific Association for Probiotics and Prebiotics recently adopted the definition proposed by the World Health Organization, "probiotics are live microorganisms that, when administrated in adequate amounts, confer a health benefit on the host" (Reid et al., 2003). A definition of probiotics applied to aquaculture has to be adapted to include reference to some specific characteristics of aquatic organisms. For example, the microbiota of aquatic organisms interacts constantly with their environment, which has a much greater influence on the health of the fish (Cahill, 1990; Romero \& Navarrete, 2006). Opportunistic pathogens can proliferate in seawater outside their host and reach a high load in the environment (Moriarty, 1998). This implies that the health status of aquatic organisms is strongly influenced by its environment. This also means that probiotics can be active in the environment as well as in the host. Probiotics are often defined as applications of entire microorganisms or components of microorganisms that are beneficial to the health of the host (Irianto \& Austin, 2002). However, based on the important influence of the environment on aquatic organisms health, the following more complete definition for probiotics has been proposed: "a live microbial adjunct which has a beneficial effect on the host by modifying the host-associated or ambient microbial community, by ensuring improved use of the feed or enhancing its nutritional value, by enhancing the host response towards disease, or by improving the quality of its ambient environment" (Verschuere et al., 2000). As defined by these authors, probiotics may include microorganisms that prevent the multiplication of pathogens in the gut, on structural surfaces, and in the growing environment, improve the water quality of the culture, contribute to food digestion, or stimulate host immune responses.

Several microorganisms has been evaluated as probiotics in aquaculture, and these have been extensively reviewed elsewhere (Verschuere et al., 2000; Irianto \& Austin, 2002; Balcázar et al., 2006a; Kesarcodiwatson et al., 2008). The most studied are lactic acid bacteria (LAB) (Lactobacillus, Carnobacterium, Enterococcus, Lactococcus, Micrococcus, Streptococcus, and Weissella) (Balcazar et al., 2008; Balcázar et al., 2007; Hagi \& Hoshino, 2009; Pérez-Sánchez et al., 2011; Vazquez et al., 2005; Villamil et al., 2002), Bacillus (Ai et al., 2011; Antony et al., 2011; Balcázar \& Rojas-Luna, 2007; Bandyopadhyay \& Das Mohapatra, 2009; Ochoa-Solano \& Olmos-Soto, 2006; Liu et al., 2009; Nakayama et al., 2009; Newaj-Fyzul et al., 2007; Olmos et al., 2011; Salinas et al., 2005; Sun et al., 2010; Vaseeharan \& Ramasamy, 2003), Vibrio (Fjellheim et al., 2007; Thompson et al., 2010), Pseudomonas (Abd El-Rhman et al., 2009; Chythanya, 2002; Das et al., 2006; Preetha et al., 2007; Ström-Bestor, Wiklund, 2011), and Aeromonas (Irianto et al., 2003; Lategan, 2004; Lategan et al., 2006; Lategan et al., 2004). Yeasts (Saccharomyces, Debaryomyces) (Abdeltawwab et al., 2008; Reyes-Becerril et al., 2008; Tovar-Ramírez et al., 2010), bacterial spore formers (Hong et al., 2005) and recently Actinobacteria have also generated interest due to their high metabolic potential (Das et al., 2010; You et al., 2007). These probiotics have been used in different aquatic organisms, such as teleost fish (Merrifield et al., 2010; Dimitroglou et al., 2011), prawns (Van Hai et al., 2009), shrimp (Farzanfar, 2006; Ninawe \& Selvin, 2009), and bivalve molluscs (Kesarcodi-Watson et al., 2008; Prado et al., 2010) and have been shown to be successful, not only for their ability to prevent disease, but also for improving digestion and growth. Many of these applications have been targeted at the early stages of development of the aquatic organisms, such as the larval stages, because these stages are more susceptible to infections (Dierckens et al., 2009; Vine et al., 2006; Avella et al., 2011; Bricknell, Dalmo, 2005; Fjellheim et al., 2007; Fjellheim et al., 2010; Nhan et al., 2010; Planas et al., 2006; Tinh et al., 2008; Zhou et al., 2009). 
The mechanisms of action of probiotics in aquaculture have been extensively reviewed (Balcázar et al., 2006; Gómez et al., 2007; Irianto, Austin, 2002; Kesarcodiwatson et al., 2008; Nayak, 2010; Prado et al., 2010; Tinh et al., 2008; Verschuere et al., 2000). Some of the proposed mechanisms that provide protection against pathogens involve the production of inhibitory compounds, competition for essential nutrients and adhesion sites, the enhancement of disease resistance and the modulation of host immune responses (Nayak, 2010; Magnadottir, 2010; Verschuere et al., 2000; Desriac et al., 2010; Balcázar et al., 2006). However, some of these probiotic activities, such as the production of inhibitory compounds in the aquatic environment, remain controversial because there is no scientific evidence for these mechanisms of action in vivo.

Interestingly, the disruption of quorum sensing in bacterial pathogens has recently been suggested as a novel strategy for use in aquaculture (Defoirdt et al., 2004; Defoirdt et al., 2008; Defoirdt et al., 2011; Merrifield et al., 2010; Tinh et al., 2008; Vine et al., 2006; Natrah et al., 2011a). Quorum sensing is a process that involves bacterial cell-to-cell communications with the participation of low molecular weight signaling molecules that elicit populationdensity-dependent responses. The signal molecules AHL ( $\mathrm{N}$-acyl homoserine lactone) and/or AI-2 (autoinducer 2) have been found to be involved in the regulation of virulence factors in many pathogenic bacteria, including fish pathogens (Federle, Bassler, 2003; Morohoshi et al., 2004; Bruhn et al., 2005; Defoirdt et al., 2005; Natrah et al., 2011b; Rasch et al., 2007; Ruwandeepika et al., 2011). Bacteria that are able to degrade quorum sensing molecules might be useful as biocontrol agents in aquaculture. To date, several bacteria of aquatic origin have been studied for their quorum quenching properties (Chu et al., 2011; Defoirdt et al., 2004; Defoirdt et al., 2008; Merrifield et al., 2010; Nakayama et al., 2009; Nhan et al., 2010; Tinh et al., 2007; Tinh et al., 2008). Marine Bacillus and Halobacillus salinus have been shown to quench the quorum sensing system of Vibrio harveyi (Musthafa et al., 2011; Teasdale et al., 2009). A Bacillus (QSI)-1-like bacteria isolated from the intestine of the fish Carassius auratus gibelio can degrade AHLs in vitro and reduced the amount of AHLs and the extracellular protease activity of Aeromonas hydrophila in coculture with the fish pathogen (Chu et al., 2011). Carp fed a diet supplemented with (QSI)-1 showed good survival after an experimental infection with Aeromonas hydrophila compared with those fed a control diet (Chu et al., 2011). Recombinant AHL-lactonase from Bacillus sp., when co-injected with the fish pathogen Aeromonas hydrophila in common carp, decreased the mortality rate and delayed the time of death of the fish (Chen et al., 2010). The Actinobacteria Streptomyces albus has been also suggested as a promising candidate for aquaculture because it was able to attenuate biofilm formation and inhibit the quorum-sensing system of Vibrio harveyi, Vibrio vulnificus, and Vibrio anguillarum (You et al., 2007).

An important aspect to be considered is that probiotics have to be innocuous or not pathogenic to the host, other aquatic organisms or human consumers. For instance, probiotics have to be free of plasmid-encoded antibiotic resistance genes. In addition, considerable further research in terms of food and environmental safety is needed.

Most of the literature about probiotics consists of reports on the study and application of a single bacterial strain. However, the conditions in which the aquatic organisms are cultured are continuously changing and have strong effects on host health. It is has been suggested that a probiotic which contained several bacteria could be more efficient at controlling bacterial pathogens (Verschuere et al., 2000; Chapman et al., 2011). This is based on the 
assumption that it would be difficult for a single bacteria to be able to remain dominant in a continuously changing environment. However, different strains could interact under a variety of conditions and be able to maintain their dominance in a dynamic way (Verschuere et al., 2000). An optimal combination of strains with different mechanisms of action may result in successful anti-pathogenic effects (Fjellheim et al., 2010). For example, rainbow trout fed a multistrain formulation containing Enterobacter cloacae and Bacillus mojavensis and then challenged with Yersinia ruckeri had a higher survival rate compared with control fish (Capkin \& Altinok, 2009).

There is a consensus in aquaculture that some microorganisms are beneficial to aquaculture organisms in terms of reducing the incidence of disease. However, despite the promising potential benefits demonstrated in the current literature, the probiotic mechanisms which mediate host benefits are poorly understood. Future studies should be focused on evaluating the mechanisms by which probiotics interact with the host and pathogens. To study the probiotic-host interaction, the use of axenic and gnotobiotic aquatic organisms have been proposed, which eliminate interference from the environmental and host microbiota, seems the most appropriate approach. Axenic organisms are raised or treated to eliminate microbes derived from parents, gametes or environment; hence they are considered germ free animals. Gnotobiotic organisms are animals harboring a known microbe or microbiota, formerly, they could be derived from a germ free animal, colonized by a known microbe. To date, very limited information has been reported about the development of axenic aquatic organisms. To our knowledge, only zebrafish (Bates et al., 2007; Rawls et al., 2004) and more recently sea bass (Dierckens et al., 2009) larvae that are free of microorganisms have been reported.

\subsection{Essential oils: Antibacterial properties and potential applications in aquaculture systems}

Essential oils (EOs) are volatile liquid fractions that contain the substances responsible for the aromas of plants; they are obtained from different organs, such as flowers, buds, seeds, leaves, twigs, bark, herbs, wood, fruits and roots (Bakkali et al., 2008). There are several methods for extracting essential oils, including expression, fermentation, enfleurage, extraction, and the use of liquid carbon dioxide or microwaves, but the steam distillation method is most commonly used for the commercial production of EOs (Burt, 2004). The chemical composition of EOs depends on the extraction method and can also vary according to conditions such as climate, soil composition, origin, season, plant organ, age and vegetative cycle stage (Abu-Darwish et al., 2011; Angioni et al., 2006; Ben Marzoug et al., 2011; Chung et al., 2011; Ennajar et al., 2011; Karakaya, 2011; Masotti et al., 2003). The composition of EOs is very complex and can include more than sixty components; however, a few major components constitute up to $85 \%$ of the EOs and generally determine their biological properties (Bakkali et al., 2008), whereas other components are present only as traces (Bader et al. 2010; Rali et al., 2007). The components include two groups of distinct biosynthetic origin that are synthesized in secondary metabolism (Nagegowda, 2010; Pichersky et al., 2006). The main group is composed of terpenes and terpenoids and the other of aromatic and aliphatic constituents, all characterized by low molecular weights (Bakkali, et al., 2008).

The primary roles of essential oils in plants are believed to be as pollinator attractors and defenses against pathogens and pests due to their antibacterial, antiviral, antifungal, and 
insecticidal effects. The essential oils of many plants contain phenolic compounds, and these comprise the majority of plant antimicrobial components (Consentino et al, 1999; Ultee et al, 2002). Among the most studied are thymol from thyme and oregano; cinnamaldehyde from cinnamon; eugenol from clove, carvacrol from oregano and anethole from anise, whose antibacterial properties have been examined in several studies (Hammer et al., 1999; Bagamboula, 2004; Burt, 2004; Calsamiglia et al., 2007; Delaquis et al., 2002; Kim et al., 1995; Lambert et al., 2001; García-García et al., 2011). Several investigations have been conducted to determine the efficiency of essential oils and their individual components in extending the shelf-life of different foods (Busatta et al., 2008; Mejlholm, Dalgaard, 2002; Kiskó, Roller, 2005; Lambert et al., 2001; Lin et al., 2004; Ponce et al., 2003; Ultee et al., 2002; Fratianni et al., 2010; Doulgeraki et al., 2011; Mastromatteo et al., 2010; Mahmoud et al., 2004; Kostaki et al., 2009; Shekarforoush et al., 2007). These reports have focused on the in vitro evaluation of the effectiveness of EOs against food-borne pathogens (Pasqua et al., 2005; Dorman, Deans, 2000; Nascimento et al., 2000; Irkin et al., 2010; de Oliveira et al., 2011; Si et al., 2006) and spoilage microorganisms (Barbosa et al., 2009; Bevilacqua et al., 2010; Pasqua et al., 2005; Dorman et al., 2000; Mejlholm \& Dalgaard 2002; Mastromatteo et al., 2010). The molecular basis of the antibacterial action of EOs is poorly understood. It has been suggested that they can disrupt the permeability of the bacterial cell membrane (Bouhdid et al., 2009; Pascua et al., 2007; Turina et al., 2006; Devi et al., 2010), leading to the disruption of the proton motive force, electron flow and active transport (Lambert et al. 2001; Ultee et al. 2002; Cox et al. 2000; Helander et al. 1998; Fisher et al., 2009). Other proposed mechanisms are related to the coagulation of cell contents (Lambert et al. 2001, Becerril et al., 2007), and recently, evidence has been provided for the inhibition of quorum sensing (Brackman et al., 2008; Kahn et al., 2009), the induction of heat shock proteins and the prevention of flagella development (Burt et al., 2007). Interestingly, cinnamaldehyde was recently found to interfere with autoinducer-2 (AI-2), which is involved in quorum sensing in Vibrio spp., by decreasing the DNA-binding ability of LuxR, resulting in several marked phenotypic changes, including reduced virulence. Because inhibitors of AI-2-based quorum sensing are rare, and given the role of AI-2 in several processes, these compounds may provide useful leads for antipathogenic drugs (Brackman et al., 2008).

Limited information is available concerning the in vivo antibacterial effects of EOs; however, interest is rising in the use of these natural compounds as an alternative to antibiotic growth promoters to improve gut health and control the pathogens carried in the guts of livestock, swine and poultry (Bampidis et al., 2006; Benchaar et al. 2008; Busquet et al., 2006; Calsamiglia et al., 2007; Jang et al., 2007; Fraser et al., 2007; McIntosh et al., 2003; Muhl \& Liebert, 2007; Cross et al., 2007; Maenner et al., 2011; Windisch et al., 2008; Yang et al., 2007). The in vivo effects of dietary treatment with EOs to control bacterial pathogens or to modify the microbiota composition are very controversial, and the effects largely depend on factors such as the type or combination of EOs used, the EO concentration, the host in which EOs are tested, and the composition and susceptibilities of the bacterial groups present in the gut.

The dietary addition of a commercial blend of essential oils, including thymol at 25 and 50 $\mathrm{mg} / \mathrm{kg}$ diet, showed a decrease in E. coli CFU in the ileo-cecal digesta in growing broiler chickens, whereas the Lactobacillus population was not affected (Jang et al. 2007). In contrast, a dietary treatment with $1000 \mathrm{mg} / \mathrm{kg}$ feed of thyme, oregano, marjoram, rosemary or yarrow herb (with an assumed $100 \mathrm{~g}$ oil $/ \mathrm{kg}$ herb) did not affect the total viable counts of 
lactic acid bacteria, coliforms, anaerobes or Clostridium perfringens in chickens from 7 to 28 days of age (Cross et al. 2007; Muhl \& Liebert, 2007). In cows, viable bacteria, cellulolytic bacteria and protozoa were not influenced by supplementation with a mixture of EOs, including thymol (Benchaar et al. 2008). The inclusion of thymol [1\% (w/w)] in a pig diet caused clear changes in the small intestine microbial community, notably decreasing Actinobacillus spp. to undetectable levels (Janczyk et al., 2008)

EOs have been studied in aquaculture as preserving agents in seafood (Kostaki et al., 2009; Lin et al., 2004; Mahmoud et al., 2004; Mejlholm, Dalgaard, 2002; Pyrgotou et al., 2010), and only recently have they been used in vivo as antibacterial agents to control bacterial infections (Yeh et al., 2009; Randrianarivelo et al., 2010). For example, the shelf-life of carp fillets has been extended by dipping fillets into a solution containing both carvacrol and thymol, leading to reduced growth and numbers of bacteria (Kim et al., 1995; Mejlholm, Dalgaard, 2002; Mahmoud et al., 2006). Trout fillet treatment with oregano EO also extended the shelf life by 7 to 8 days for fresh trout fillets (Pyrgotou et al., 2010).

Examples of the in vivo use of EOs in aquaculture systems are scarce but promising. The few studies that exist have reported the effects of EOs on shrimp and some fish. A recent report by Yeh et al. (2009) reported that EOs from Cinnamomum kanehirae (stout camphor tree) showed antibacterial effects against different pathogens of aquatic animals, and shrimp (Litopenaeus vannamei) treated with hot-water extracts from twigs of Cinnamomum kanehirae showed a significant decrease in their sensitivity to Vibrio alginolyticus (Yeh et al., 2009). When the EO of Cinnamosma fragrans, an endemic plant to Madagascar, was added directly to the water tank, there was an increase in the survival of the shrimp larvae (Penaeus monodon) concomitant with a decrease in bacterial concentration (Randrianarivelo et al., 2010). Similarly, two EOs of C. fragrans (B8: linalool-type and B143: 1,8-cineole-type) reduced the total heterotrophic aerobic bacteria and the Vibrio concentrations in the rearing water of P. monodon shrimp larvae (Sarter et al., 2011)

The effects of supplementing diets with acetone extract $(1 \% \mathrm{w} / \mathrm{w})$ from four medicinal plants (Bermuda grass, Cynodon dactylon; beal, Aegle marmelos; wintercherry, Withania somnifera; and ginger, Zingiber officinale) were evaluated in tilapia (Oreochromis mossambicus). The results showed that tilapia fed the plant extracts showed improvements in their growth, and their non-specific immune responses were stimulated, as indicated by increases in leucocrit value, phagocytic index and lysozyme activity. The acetone extract from $W$. somnifera showed the strongest inhibition of Vibrio spp. and Photobacterium damselae growth. A challenge test with $V$. vulnificus showed $100 \%$ mortality in O. mossambicus fed the control diet by day 15 , whereas the fish fed the experimental diets registered only $63-80 \%$ mortality at the end of challenge experiment (30 days) (Immanuel et al., 2009). Interestingly, channel catfish (Ictalurus punctatus) fed with the natural oregano EO extracted from Origanum heracleoticum had the lowest mortality following an Aeromonas hydrophila infection compared with fish fed a combination of carvacrol and thymol, which are the principal active components of oregano EO (Zheng et al., 2009). These results highlight the fact that the use of the entire EO is more effective than treating with a combination of its principal components.

It is important to evaluate the effect of EOs on the normal gut microbiota. Recently, Navarrete et al. (2010) evaluated the effects of a diet supplemented with Thymus vulgaris 
essential oil (TVEO) on the composition of the rainbow trout intestinal microbiota using molecular profiling methods based on 16S rRNA gene analysis (restriction fragment length polymorphism (RFLP)) and PCR-temporal temperature gradient electrophoresis (PCRTTGE). No significant changes ( $P>0.05$ ) were detected in the RFLP and TTGE profiles of TVEO-treated trout compared with controls, indicating that the dominant microbiota was not affected by the EO. In addition, in vitro determination of the antibacterial activity of TVEO was performed using several bacteria isolated from the gut of healthy trout and some fish pathogens. The inhibitory concentrations for all bacteria tested were higher than the TVEO levels used in trout, which may explain the in vivo results. The MICs were similar to those previously reported (Cosentino et al. 1999; Burt, 2004). Notably, some pathogenic bacteria, such as Lactococcus piscium, were clearly more susceptible to TVEO than those isolates belonging to the indigenous microbiota. It should be noted that the level of TVEO required to inhibit bacterial pathogens $(480 \mathrm{mg} / \mathrm{L})$ is higher than the level used in the in vivo study $(20 \mathrm{mg}$ TVEO $/ \mathrm{kg}$ feed). Therefore, more in vivo studies are needed to evaluate the effects of higher TVEO concentrations on gut bacteria. It will also be necessary to evaluate whether these higher concentrations can alter feed flavor or induce toxic responses in the fish (Stroh et al. 1998). To enhance shelf life and avoid the degradation of EO in supplemented feed, the encapsulation of EOs could be a plausible means of delivering active EOs into the fish gut, as this would reduce interactions with the food matrix and possibly reduce any toxic effects. This approach has recently been evaluated, and the application of this method to aquaculture is highly promising (Wang et al., 2009; Piva et al., 2007; Pérez-Conesa et al., 2011; van Vuuren et al., 2010; Donsi et al., 2011).

\subsection{Phage therapy as a potential therapy in aquaculture}

Bacteriophages are defined as viruses that can infect, multiply in and kill susceptible bacteria. They are both ubiquitous and abundant in the environment, especially in seawater, in which the total numbers of viruses frequently exceeds the bacterial concentration by a factor of 10 (Børsheim, 1993). Since their discovery in 1915, phages have been studied for their therapeutic properties and ability to control infectious bacteria; however these studies were later abandoned due to the introduction of cheap, broad-spectrum antibiotics. Recently, after the increase in bacterial antibiotic resistance, phage therapy has reappeared as an effective alternative to the use of antibiotics. To date, several early studies have shown the therapeutic and prophylactic effects of phage therapy in animals and humans (Mathur et al., 2003). Phages have several advantages over other therapeutic agents: 1) they have specific narrow host ranges, meaning that they do not harm the normal intestinal microbiota; 2) they can self-replicate in the bacterial target, which eliminates the need for multiple administrations and 3) there have been no reports of side effects (Mathur et al., 2003; Nakai, Park, 2002).

The use of phage therapy in aquaculture began with the work of Nakai et al. (1999) and has been recently reviewed (Almeida et al., 2009). The first studies evaluated the ability of phages to prevent the infection of yellowtail (Seliora quinqueradiata) and ayu (Plecoglossus altivelis) with Lactococcus garvieae and Pseudomonas plecoglossicida, respectively. Phages can easily enter the fish body through the skin and gills; phages can be detected in the kidney after dipping fish in phage solution. Bath administration of phages will be effective for those fish in which infection is initiated by bacterial colonization on the skin and gills (Nakai \& 
Park, 2002). Administration of phages through feed will be advantageous for infections in which the oral route is the major route for pathogen transmission, as is the case for $L$. garvieae infection of yellowtail and P. plecoglossicida infection of ayu (Nakai \& Park, 2002).

An anti-Lactococcus garvieae phage was intraperitoneally or orally administered to yellowtail and protected the fish from experimental L. garvieae infection, suggesting a potential use for the phage in controlling this disease (Nakai et al., 1999). The oral administration of phageimpregnated feed to ayu (Plecoglossus altivelis) resulted in protection against infection with Pseudomonas plecoglossicida, which quickly disappeared from the kidneys of the phagetreated fish (Park et al., 2000). In the presence of phages, bacterial counts in freshwater were also low. These results suggest the feasibility of using phages to control the disease caused by $P$. plecoglossicida, the causative agent of bacterial hemorrhagic ascites disease in cultured ayu fish (Park et al., 2000). Furthermore, in another study, a mixture of two phages induced the highest protection in ayu ( $P$. altivelis) against water-borne infection with $P$. plecoglossicida compared with the administration of one phage alone (Park \& Nakai, 2003). Interestingly, neither phage-resistant organisms nor phage-neutralizing antibodies were detected in diseased fish or apparently healthy fish, respectively.

Phage therapy has also been successfully used to protect against Vibrio infection in a shrimp and prawn hatchery. A bacteriophage of Vibrio harveyi was isolated from shrimp farm water from the west coast of India and showed a broad lytic activity against $V$. harveyi isolates. Shrimp larvae infected with $V$. harveyi showed a higher rate of survival in the presence of the bacteriophage compared with the control. Treatment with the bacteriophage in field trials where there was a natural outbreak of $V$. harveyi improved larval survival and reduced the $V$. harveyi counts in hatchery tanks (Vinod et al., 2006). Shivu et al. (Shivu et al., 2007) also isolated four phages from oyster tissue and a shrimp hatchery that had lytic activity against $V$. harveyi. These bacteriophages were effective in controlling the population of $V$. harveyi in hatchery systems and enhanced the survival of shrimp (Penaeus monodon). Bacteriophages with lytic activity against $V$. harveyi were isolated from prawn farm samples. Purified phages of the family Siphoviridae had a clear lytic ability and no apparent transducing properties, indicating they are appropriate for phage therapy (Crothers-Stomps et al., 2010). Although several phages isolated from hatcheries and water from aquaculture systems showed highly lytic activity against $V$. harveyi (Shivu et al., 2007), some phages that infect $V$. harveyi occur in a hatchery and co-exist with $V$. harveyi cells and are unable to control the outbreak of luminescent bacterial disease in a shrimp system Chrisolite et al. (2008).

More recently, Imbeault et al. (2006) confirmed the earlier results of Park and Nakai (Park \& Nakai, 2003) showing that a bacteriophage mixture was successfully used to prevent Aeromonas salmonicida infection (furunculosis) in brook trout. They showed that more than one phage could infect $A$. salmonicida and that a mutant resistant to one phage was sensitive to one or more other phages. Resistant bacteria had a shorter generation time than the original strain and their replication success was very low (Imbeault et al., 2006). This highlights the necessity of using more than one phage to avoid bacterial resistance. In contrast, Atlantic salmon was not protected by the application of bacteriophages from $A$. salmonicida furunculosis, which could be due to the limited duration of survival of bacteriophages in the target animal, limiting the effectiveness of the treatment (VernerJeffreys et al., 2007). 
In order to control Flavobacterium psychrophilum, the causative agent of systemic bacterial coldwater disease (CWD), a number of lytic phages of F. psychrophilum that infect trout, were isolated and showed a broad host range on F. psychrophilum, suggesting that they could be used in phage therapy (Stenholm et al., 2008). Another recent study that involved searching for phages using the enrichment method on pond water collected from Japanese ayu farms showed that the phage PFpW-3 had high infectivity for F. psychrophilum and demonstrated sufficient survivability in the stability tests. This study may be the basis for further evaluation of phage therapy in the treatment of CWD in Japanese ayu farms (Kim et al., 2010).

Walakira et al. isolated two lytic bacteriophages specific for Edwardsiella ictaluri which causes enteric septicemia of catfish (Walakira et al, 2008). Each E. ictaluri strain tested was susceptible to phage infection with variable efficiency, but the phages showed no evidence of lysogeny, and no plaques were detected on other bacterial species, demonstrating their potential use as biotherapeutic and diagnostic agents associated with enteric septicemia of catfish.

Besides the broad range of advantages, the following limitations of the use of phages have been identified (Mathur et al., 2003): 1) the induction of toxin genes, 2) the rapid release of bacterial endotoxins due to the lytic effect of the phage, 3) the risk that phages might mediate genetic exchange among bacteria, i.e. transduction or phage conversion, 4) the maintenance of phages by regular propagation needs expertise and an established set up, 5) the development of antibodies against phages may also lead to their decreased effectiveness, 6) the cost 7) some temperate phages contribute to bacterial virulence, 8) the rapid appearance of phage-resistant bacteria, 9) the presence of a disease outbreak with unknown bacteria in which high specificity may be a problem and 10) phage therapy cannot be used for intracellular bacteria because the phages are continuously cleared by the spleen, liver and other filtering organs (recticulo-endothelial system).

Despite the limitations mentioned, neutralizing antibodies have not been detected to date. Conversely, the low immunogenicity of phages in fish might provide an advantage for phage therapy in fish (Nakai et al, 2002). In addition, although phage-resistant mutants are uncommon, the use of a multiphage therapy could reduce the resistance frequency and avoid resistance (Levin \& Bull, 2004).

Recently, phage therapy has generated a great deal of interest, and this interest has led to the formation of a strong network for the development of phage therapy in aquaculture (AQUAPHAGE, http://lib.bioinfo.pl/projects/view/26098). The implementation of this initiative involves a common project focused on the identification and exploitation of phages specific for bacterial pathogens that constitute serious threats for both freshwater and marine aquaculture. The target bacteria are Listonella anguillarum and $V$. harveyi, pathogens of Mediterranean aquaculture species (European sea bass and gilthead sea bream); Flavobacterium psychrophilum, a serious trout pathogen; and Aeromonas salmonicida, an obligate bacterial pathogen of Atlantic salmon.

\section{Conclusion}

Intensive fish farming has promoted the spread of several bacterial diseases, which in turn has led to the increased use of antimicrobials. Concerns about the consequences of antibiotic 
use on public health have encouraged the development of strict regulations controlling the use of antibiotics and have led to only a few antibiotics being licensed for use in aquaculture.

The high proportions of antibiotic-resistant bacteria that persist in sediments and farm environments may provide a threat to fish farms because they can serve as sources of antibiotic-resistance genes for fish pathogens in the vicinity of the farms. Because resistant bacteria may be transferred to humans and are capable of transferring their resistance elements to opportunistic human pathogens, the implementation of efficient strategies to contain and manage resistance-gene emergence and spread is critical. In addition to the potential effects on human health, inefficiencies in antibiotic treatment of fish illnesses lead to significant economic losses.

One strategy for reducing antibiotic use in aquaculture is to implement rearing practices that minimize the level of stress on the fish and that reduce the likelihood that infections requiring antibiotic treatment will occur.

Several alternatives to antibiotics have been developed; including probiotics, phage therapy and essential oils, and some of these have been successfully used to control bacterial infections in aquaculture facilities. These microorganisms, compounds, and/or their components are gaining increasing interest because of their relatively safe status, wide acceptance by consumers and their potential for multipurpose uses. Although the application of these alternatives to aquaculture is very promising, further studies are needed to gain more insight about their mechanisms of actions, to improve their stability and to evaluate their impact on the environment and the host microbiota.

\section{Acknowledgments}

This work has been supported by FONDECYT grants No. 1110253, 11090102 and 3100075 from CONICYT-Chile.

\section{References}

Abd El-Rhman, Azza M; Khattab, Yassir a E; Shalaby, Adel M E (2009): „Micrococcus luteus and Pseudomonas species as probiotics for promoting the growth performance and health of Nile tilapia, Oreochromis niloticus.". In: Fish \& shellfish immunology. Elsevier Ltd 27 (2), pp. 175-80.

Abdeltawwab, M; Abdelrahman, A; Ismael, N (2008): „Evaluation of commercial live bakers' yeast, Saccharomyces cerevisiae as a growth and immunity promoter for Fry Nile tilapia, Oreochromis niloticus (L.) challenged in situ with Aeromonas hydrophila“. In: Aquaculture. 280 (1-4), pp. 185-189.

Abu-Darwish, Mohammad S et al. (2011): "Seasonal variation in essential oil yield and composition from Thymus vulgaris L. during different growth stages in the south of Jordan“. In: Natural Product Research. Taylor \& Francis pp. 1-8.

Ai, Qinghui et al. (2011): „Effects of dietary supplementation of Bacillus subtilis and fructooligosaccharide on growth performance, survival, non-specific immune response and disease resistance of juvenile large yellow croaker, Larimichthys crocea“. In: Aquaculture. Elsevier B.V. 317 (1-4), pp. 155-161. 
Akinbowale, O L; Peng, H; Barton, M D (2007): „Diversity of tetracycline resistance genes in bacteria from aquaculture sources in Australia.". In: Journal of applied microbiology. 103 (5), pp. 2016-25.

Alderman, D J; Hastings, T S (1998): "Antibiotic use in aquaculture: development of antibiotic resistance - potential for consumer health risks •“. In: International Journal of Food Science and Technology. (July 1997), pp. 139-155.

Almeida, Adelaide et al. (2009): „Phage therapy and photodynamic therapy: low environmental impact approaches to inactivate microorganisms in fish farming plants.“. In: Marine drugs. 7 (3), pp. 268-313.

Amann, R I; Ludwig, W; Schleifer, K H (1995): „Phylogenetic identification and in situ detection of individual microbial cells without cultivation.“. In: Microbiological reviews. 59 (1), pp. 143-69.

Angioni, Alberto et al. (2006): „Chemical composition, seasonal variability, and antifungal activity of Lavandula stoechas L. ssp. stoechas essential oils from stem/leaves and flowers.". In: Journal of agricultural and food chemistry. 54 (12), pp. 4364-70.

Antony, Swapna P. et al. (2011): "Antimicrobial peptide gene expression in tiger shrimp, Penaeus monodon in response to gram-positive bacterial probionts and white spot virus challenge“. In: Aquaculture. Elsevier B.V. 316 (1-4), pp. 6-12.

Austin, B.; Al-Zahrani, a. M. J. (1988): „The effect of antimicrobial compounds on the gastrointestinal microflora of rainbow trout, Salmo gairdneri Richardson". In: Journal of Fish Biology. 33 (1), pp. 1-14.

Avella, Matteo a. et al. (2011): „Use of Enterococcus faecium to improve common sole (Solea solea) larviculture“. In: Aquaculture. Elsevier B.V. 315 (3-4), pp. 384-393.

Bader, Ammar; Cioni, Pier Luigi; Flamini, Guido (2010): „GC-MS analysis of the essential oils of ripe fruits, roots and flowering aerial parts of Elaeoselinum asclepium subsp. meoides growing in Sicily.“. In: Natural product communications. 5 (7), pp. 11111114.

Bagamboula, C (2004): „Inhibitory effect of thyme and basil essential oils, carvacrol, thymol, estragol, linalool and p-cymene towards Shigella sonnei and S. flexneri“. In: Food Microbiology. 21 (1), pp. 33-42.

Bakkali, F et al. (2008): „Biological effects of essential oils--a review.“. In: Food and chemical toxicology : an international journal published for the British Industrial Biological Research Association. 46 (2), pp. 446-75.

Balcazar, J et al. (2008): „Characterization of probiotic properties of lactic acid bacteria isolated from intestinal microbiota of fish“. In: Aquaculture. 278 (1-4), pp. 188-191.

Balcázar, José Luis et al. (2006): „The role of probiotics in aquaculture.“. In: Veterinary microbiology. 114 (3-4), pp. 173-86.

Balcázar, José Luis et al. (2007): „In vitro competitive adhesion and production of antagonistic compounds by lactic acid bacteria against fish pathogens.". In: Veterinary microbiology. 122 (3-4), pp. 373-80.

Balcázar, José Luis; Rojas-Luna, Tyrone (2007): „Inhibitory activity of probiotic Bacillus subtilis UTM 126 against vibrio species confers protection against vibriosis in juvenile shrimp (Litopenaeus vannamei).“. In: Current microbiology. 55 (5), pp. 409-12. 
Bampidis, V a et al. (2006): „Effect of dried oregano leaves versus neomycin in treating newborn calves with colibacillosis.“. In: Journal of veterinary medicine. A, Physiology, pathology, clinical medicine. 53 (3), pp. 154-6.

Bandyopadhyay, Partha; Mohapatra, Pradeep K Das (2009): „Effect of a probiotic bacterium Bacillus circulans PB7 in the formulated diets: on growth, nutritional quality and immunity of Catla catla (Ham.).“. In: Fish physiology and biochemistry. 35 (3), pp. 467-78.

Barton, Bruce a (2002): „Stress in fishes: a diversity of responses with particular reference to changes in circulating corticosteroids.". In: Integrative and comparative biology. 42 (3), pp. 517-25.

Bates, J M (2006): ", Distinct signals from the microbiota promote different aspects of zebrafish gut differentiation“. In: Dev. Biol. 297 , p. 374e386.

Bates, Jennifer M et al. (2007): „Intestinal alkaline phosphatase detoxifies lipopolysaccharide and prevents inflammation in zebrafish in response to the gut microbiota.". In: Cell host \& microbe. 2 (6), pp. 371-82.

Ben Marzoug, Hajer Naceur et al. (2011): „Eucalyptus oleosa essential oils: chemical composition and antimicrobial and antioxidant activities of the oils from different plant parts (stems, leaves, flowers and fruits).". In: Molecules (Basel, Switzerland). 16 (2), pp. 1695-709.

Benchaar, C et al. (2008): „A review of plant-derived essential oils in ruminant nutrition and production“. In: Animal Feed Science and Technology. 145 (1-4), pp. 209-228.

Borsheim, Knut Yngve (1993): „Native marine bacteriophages“. In: FEMS Microbiology Letters. 102 (3-4), pp. 141-159.

Bricknell, Ian; Dalmo, Roy A (2005): "The use of immunostimulants in fish larval aquaculture.“. In: Fish \& shellfish immunology. 19 (5), pp. 457-72.

Bruhn, Jesper B et al. (2005): "Quorum sensing signal molecules (acylated homoserine lactones) in gram-negative fish pathogenic bacteria.". In: Diseases of aquatic organisms. 65 (1), pp. 43-52.

Burridge, Les et al. (2010): "Chemical use in salmon aquaculture: A review of current practices and possible environmental effects“. In: Aquaculture. Elsevier B.V. 306 (14), pp. 7-23.

Burt, Sara (2004): „Essential oils: their antibacterial properties and potential applications in foods--a review.“. In: International journal of food microbiology. 94 (3), pp. 223-53.

Busatta, C et al. (2008): "Application of Origanum majorana L. essential oil as an antimicrobial agent in sausage.“. In: Food microbiology. 25 (1), pp. 207-11.

Busquet, $\mathrm{M}$ et al. (2006): „Plant extracts affect in vitro rumen microbial fermentation.“. In: Journal of dairy science. 89 (2), pp. 761-71.

Cabello, Felipe C (2006): „Heavy use of prophylactic antibiotics in aquaculture: a growing problem for human and animal health and for the environment.". In: Environmental microbiology. 8 (7), pp. 1137-44.

Cahill, Marian (1990): „Bacterial flora of fishes: A review“. In: Microbial Ecology. Springer New York 19 (1), pp. 21-41.

Caipang, Christopher Marlowe a et al. (2009): „In vivo modulation of immune response and antioxidant defense in Atlantic cod, Gadus morhua following oral administration of oxolinic acid and florfenicol.“. In: Comparative biochemistry and physiology. Toxicology \& pharmacology : CBP. Elsevier Inc. 150 (4), pp. 459-64. 
Calsamiglia, S et al. (2007): „Invited review: Essential oils as modifiers of rumen microbial fermentation.". In: Journal of dairy science. 90 (6), pp. 2580-95.

Capkin, E; Altinok, I (2009): „Effects of dietary probiotic supplementations on prevention/treatment of yersiniosis disease.". In: Journal of applied microbiology. 106 (4), pp. 1147-53.

Carpenter, Christopher F; Chambers, Henry F (2004): „Daptomycin: another novel agent for treating infections due to drug-resistant gram-positive pathogens.". In: Clinical infectious diseases: an official publication of the Infectious Diseases Society of America. 38 (7), pp. 994-1000.

Carson, M.C. Bullock, G.; Bebak-Williams, J. (2002): „Determination of oxytetracycline residues in matrixes from a freshwater recirculating aquaculture system.“. In: journal of AOAC International. 85 (2), pp. 341-348.

Chapman, C M C; Gibson, G R; Rowland, I (2011): „Health benefits of probiotics: are mixtures more effective than single strains?". In: European journal of nutrition. 50 (1), pp. 1-17.

Chen, Ruidong et al. (2010): „High yield expression of an AHL-lactonase from Bacillus sp. B546 in Pichia pastoris and its application to reduce Aeromonas hydrophila mortality in aquaculture. “. In: Microbial cell factories. 9 , p. 39.

Chrisolite, B et al. (2008): „Distribution of luminescent Vibrio harveyi and their bacteriophages in a commercial shrimp hatchery in South India“. In: Aquaculture. 275 (1-4), pp. 13-19.

Chu, W et al. (2011): „Isolation and characterization of new potential probiotic bacteria based on quorum-sensing system.". In: Journal of applied microbiology. 110 (1), pp. 202-8.

Chung, Ill-Min et al. (2011): „Composition of the essential oil constituents from leaves and stems of Korean Coriandrum sativum and their immunotoxicity activity on the Aedes aegypti L.“. In: Immunopharmacology and Immunotoxicology. Informa Healthcare pp. 1-5.

Chythanya, R (2002): „Inhibition of shrimp pathogenic vibrios by a marine Pseudomonas I-2 strain“. In: Aquaculture. 208 (1-2), pp. 1-10.

Cosentino, S et al. (1999): „In-vitro antimicrobial activity and chemical composition of Sardinian Thymus essential oils.“. In: Letters in applied microbiology. 29 (2), pp. 130-5.

Cross, D E et al. (2007): "The effect of herbs and their associated essential oils on performance, dietary digestibility and gut microflora in chickens from 7 to 28 days of age.“. In: British poultry science. 48 (4), pp. 496-506.

Crothers-Stomps, C et al. (2010): "Isolation of lytic bacteriophage against Vibrio harveyi.“. In: Journal of applied microbiology. 108 (5), pp. 1744-50.

Das, B et al. (2006): „Antagonistic activity of cellular components of Pseudomonas species against Aeromonas hydrophila“. In: Aquaculture. 253 (1-4), pp. 17-24.

Das, Surajit; Ward, Louise R.; Burke, Chris (2010): „Screening of marine Streptomyces spp. for potential use as probiotics in aquaculture“. In: Aquaculture. Elsevier B.V. 305 (1-4), pp. 32-41.

Defoirdt, Tom et al. (2004): „Disruption of bacterial quorum sensing: an unexplored strategy to fight infections in aquaculture“. In: Aquaculture. 240 (1-4), pp. 69-88. 
Defoirdt, Tom et al. (2005): „The impact of mutations in the quorum sensing systems of Aeromonas hydrophila, Vibrio anguillarum and Vibrio harveyi on their virulence towards gnotobiotically cultured Artemia franciscana.". In: Environmental microbiology. 7 (8), pp. 1239-47.

Defoirdt, Tom et al. (2007): "Alternatives to antibiotics to control bacterial infections: luminescent vibriosis in aquaculture as an example.". In: Trends in biotechnology. 25 (10), pp. 472-9.

Defoirdt, Tom et al. (2008): "Quorum sensing and quorum quenching in Vibrio harveyi: lessons learned from in vivo work.“. In: The ISME journal. 2 (1), pp. 19-26.

Defoirdt, Tom; Sorgeloos, Patrick; Bossier, Peter (2011): "Alternatives to antibiotics for the control of bacterial disease in aquaculture.". In: Current opinion in microbiology. 14 (3), pp. 251-8.

Delaquis, Pascal J et al. (2002): „Antimicrobial activity of individual and mixed fractions of dill, cilantro, coriander and eucalyptus essential oils.“. In: International journal of food microbiology. 74 (1-2), pp. 101-9.

Depaola, a; Peller, J T; Rodrick, G E (1995): „Effect of oxytetracycline-medicated feed on antibiotic resistance of gram-negative bacteria in catfish ponds.". In: Applied and environmental microbiology. 61 (9), p. 3513.

Desriac, Florie et al. (2010): „Bacteriocin as weapons in the marine animal-associated bacteria warfare: inventory and potential applications as an aquaculture probiotic.“. In: Marine drugs. 8 (4), pp. 1153-77.

Dierckens, K et al. (2009): „Development of a bacterial challenge test for gnotobiotic sea bass (Dicentrarchus labrax) larvae.“. In: Environmental microbiology. 11 (2), pp. 526-33.

Dimitroglou, Arkadios et al. (2011): „Microbial manipulations to improve fish health and production--a Mediterranean perspective.“. In: Fish \& shellfish immunology. Elsevier Ltd 30 (1), pp. 1-16.

Donsì, Francesco et al. (2011): „Design of nanoemulsion-based delivery systems of natural antimicrobials: Effect of the emulsifier.". In: Journal of biotechnology.

Doulgeraki, Agapi I; Paramithiotis, Spiros; Nychas, George-John E (2011): „Characterization of the Enterobacteriaceae community that developed during storage of minced beef under aerobic or modified atmosphere packaging conditions.“. In: International journal of food microbiology. Elsevier B.V. 145 (1), pp. 77-83.

Duran, G.M; Marshall, Douglas (2005): „Ready-to-eat shrimp as an international vehicle of antibiotic-resistant bacteria.“. In: Journal of Food Protection. 68 (11), pp. 2395-2401.

Ellingsen, Odd F et al. (2002): „Dosage regime experiments with oxolinic acid and flumequine in Atlantic salmon (Salmo salar L) held in seawater". In: Aquaculture. 209 (1-4), pp. 19-34.

Ennajar, Monia et al. (2011): „Influence of the process, season, and origin on volatile composition and antioxidant activity of Juniperus phoenicea L. leaves essential oils.“. In: Journal of food science. 76 (2), pp. C224-30.

FAO Fisheries and Aquaculture Department Food And Agriculture Organization Of The United Nations. 2010. The State of World Fisheries and Aquaculture.

Farzanfar, Ali (2006): „The use of probiotics in shrimp aquaculture.“. In: FEMS immunology and medical microbiology. 48 (2), pp. 149-58.

Federle, Michael J; Bassler, Bonnie L (2003): „Interspecies communication in bacteria“. In: Journal of Clinical Investigation. 112 (9), pp. 1291-1299. 
Fernández-Alarcón, C et al. (2010): „Detection of the floR Gene in a Diversity of Florfenicol Resistant Gram-Negative Bacilli from Freshwater Salmon Farms in Chile.“. In: Zoonoses and public health. 57 , pp. 181-188.

Fjellheim, a et al. (2007): "Vibrionaceae dominates the microflora antagonistic towards Listonella anguillarum in the intestine of cultured Atlantic cod (Gadus morhua L.) larvae“. In: Aquaculture. 269 (1-4), pp. 98-106.

Fjellheim, Anders Jón et al. (2010): „Selection of candidate probionts by two different screening strategies from Atlantic cod (Gadus morhua L.) larvae.“. In: Veterinary microbiology. 144 (1-2), pp. 153-9.

Fraser, G R et al. (2007): „Assessment of the effects of cinnamon leaf oil on rumen microbial fermentation using two continuous culture systems.". In: Journal of dairy science. 90 (5), pp. 2315-28.

Fratianni, Florinda et al. (2010): „Preservation of chicken breast meat treated with thyme and balm essential oils.“. In: Journal of food science. 75 (8), pp. M528-35.

Froehlicher, Mirjam et al. (2009): „Zebrafish (Danio rerio) neuromast: promising biological endpoint linking developmental and toxicological studies.“. In: Aquatic toxicology (Amsterdam, Netherlands). 95 (4), pp. 307-19.

García-García, Rebeca; López-Malo, Aurelio; Palou, Enrique (2011): „Bactericidal action of binary and ternary mixtures of carvacrol, thymol, and eugenol against Listeria innocua.“. In: Journal of food science. 76 (2), pp. M95-100.

Giraud, Etienne et al. (2006): „Survey of antibiotic resistance in an integrated marine aquaculture system under oxolinic acid treatment.". In: FEMS microbiology ecology. 55 (3), pp. 439-48.

Gómez, Geovanny; Balcázar, José Luis; Shen, M A (2007): „Probiotics as Control Agents in Aquaculture“. In: Journal of Ocean University of China. 6 (1), pp. 76-79.

Grondel, J.L. Gloudemans, A.G.M; Muiswinkel, Willem B van (1985): „The influence of antibiotics on the immune system. II. Modulation of fish leukocyte responses in culture“. In: Veterinary Immunology and Immunopathology. 6 (3), pp. 251-260.

Hagi, Tatsuro; Hoshino, Takayuki (2009): "Screening and Characterization of Potential Probiotic Lactic Acid Bacteria from Cultured Common Carp Intestine“. In: Bioscience, Biotechnology, and Biochemistry. 73 (7), pp. 1479-1483.

Hai, Ngo Van; Buller, Nicky; Fotedar, Ravi (2009): "The use of customised probiotics in the cultivation of western king prawns (Penaeus latisulcatus Kishinouye, 1896).“. In: Fish \& shellfish immunology. Elsevier Ltd 27 (2), pp. 100-4.

Hammer, K a; Carson, C F; Riley, T V (1999): „Antimicrobial activity of essential oils and other plant extracts.“. In: Journal of applied microbiology. 86 (6), pp. 985-90.

Hentschel, Dirk M et al. (2005): „Acute renal failure in zebrafish: a novel system to study a complex disease.“. In: American journal of physiology. Renal physiology. 288 (5), pp. F923-9.

Hong, Huynh a; Duc, Le Hong; Cutting, Simon M (2005): „The use of bacterial spore formers as probiotics.“. In: FEMS microbiology reviews. 29 (4), pp. 813-35.

Huber, I. et al. (2004): „Phylogenetic analysis and in situ identification of the intestinal microbial community of rainbow trout (Oncorhynchus mykiss, Walbaum) “. In: Journal of Applied Microbiology. 96 (1), pp. 117-132. 
Imbeault, Sandra et al. (2006): „Using Bacteriophages to Prevent Furunculosis Caused by Aeromonas salmonicida in Farmed Brook Trout“. In: Journal of Aquatic Animal Health. 18 (3), pp. 203-214.

Immanuel, G et al. (2009): „Dietary medicinal plant extracts improve growth, immune activity and survival of tilapia Oreochromis mossambicus.". In: Journal of fish biology. 74 (7), pp. 1462-75.

Irianto, A; Austin, B (2002): „Review Probiotics in aquaculture“. In: Journal of Fish Diseases. (1997), pp. 633-642.

Irianto, a; Robertson, P a W; Austin, B (2003): „Oral administration of formalin-inactivated cells of Aeromonas hydrophila A3-51 controls infection by atypical A. salmonicida in goldfish, Carassius auratus (L.)“. In: Journal of Fish Diseases. 26 (2), pp. 117-120.

Jacobs, Liezl; Chenia, Hafizah Y (2006): „Characterization of integrons and tetracycline resistance determinants in Aeromonas spp . isolated from South African aquaculture systems". In: International Journal of Food Microbiology.

Janczyk, Pawel et al. (2008): „Effect of thymol on microbial diversity in the porcine jejunum.“. In: International journal of food microbiology. 126 (1-2), pp. 258-61.

Jang, I et al. (2007): „Effect of a commercial essential oil on growth performance, digestive enzyme activity and intestinal microflora population in broiler chickens". In: Animal Feed Science and Technology. 134 (3-4), pp. 304-315.

Karakaya, Sibel et al. (2011): „Antioxidant and Antimicrobial Activities of Essential Oils Obtained from Oregano (Origanum vulgare ssp. hirtum) by Using Different Extraction Methods“. In: Journal of Medicinal Food. Mary Ann Liebert, Inc., publishers 14 (6), pp. 645-652.

Karunasagar, Iddya et al. (1994): „Mass mortality of Penaeus monodon larvae due to antibiotic-resistant Vibrio harveyi infection“. In: Aquaculture. 128 (3-4), pp. 203209.

Kerry, J (1997): „Changes in oxytetracycline resistance of intestinal microflora following oral administration of this agent to Atlantic salmon (Salmo salar L.) smolts in a marine environment". In: Aquaculture. 157 (3-4), pp. 187-195.

Kesarcodiwatson, a et al. (2008): „Probiotics in aquaculture: The need, principles and mechanisms of action and screening processes“. In: Aquaculture. 274 (1), pp. 1-14.

Kim, Jeongmok; Marshall, Maurice R.; Wei, Cheng-i (1995): „Antibacterial activity of some essential oil components against five foodborne pathogens". In: Journal of Agricultural and Food Chemistry. 43 (11), pp. 2839-2845.

Kim, Ji Hyung et al. (2010): „Isolation and identification of bacteriophages infecting ayu Plecoglossus altivelis altivelis specific Flavobacterium psychrophilum.“. In: Veterinary microbiology. 140 (1-2), pp. 109-15.

Kiskó, Gabriella; Roller, Sibel (2005): „Carvacrol and p-cymene inactivate Escherichia coli O157:H7 in apple juice.". In: BMC microbiology. 5 , p. 36.

Kostaki, Maria et al. (2009): "Combined effect of MAP and thyme essential oil on the microbiological, chemical and sensory attributes of organically aquacultured sea bass (Dicentrarchus labrax) fillets.“. In: Food microbiology. Elsevier Ltd 26 (5), pp. 475-82.

Kumarasamy, Karthikeyan K et al. (2010): „Emergence of a new antibiotic resistance mechanism in India, Pakistan, and the UK: a molecular, biological, and epidemiological study.“. In: The Lancet infectious diseases. 10 (9), pp. 597-602. 
Lalumera, Giorgia Mary et al. (2004): „Preliminary investigation on the environmental occurrence and effects of antibiotics used in aquaculture in Italy.". In: Chemosphere. 54 (5), pp. 661-8.

Lambert, R J et al. (2001): "A study of the minimum inhibitory concentration and mode of action of oregano essential oil, thymol and carvacrol.“. In: Journal of applied microbiology. 91 (3), pp. 453-62.

Lategan, M (2004): „Biocontrol of saprolegniosis in silver perch Bidyanus bidyanus (Mitchell) by Aeromonas media strain A199“. In: Aquaculture. 235 (1-4), pp. 77-88.

Lategan, M.J. et al. (2006): „An inhibitory substance produced by Aeromonas media A199, an aquatic probiotic". In: Aquaculture. 254 (1-4), pp. 115-124.

Lategan, M.J. Torpy, F.R.; Gibson, L.F. (2004): „Control of saprolegniosis in the eel Anguilla australis Richardson, by Aeromonas media strain A199“. In: Aquaculture. 240 (1-4), pp. 19-27.

Levin, Bruce R; Bull, James J (2004): „Population and evolutionary dynamics of phage therapy.". In: Nature reviews. Microbiology. 2 (2), pp. 166-73.

Lin, Y T; Labbe, R G; Shetty, Kalidas (2004): „Inhibition of Listeria monocytogenes in Fish and Meat Systems by Use of Oregano and Cranberry Phytochemical Synergies“. In: Society. 70 (9), pp. 5672-5678.

Liu, C-H et al. (2009): "Improvement in the growth performance of white shrimp, Litopenaeus vannamei, by a protease-producing probiotic, Bacillus subtilis E20, from natto.". In: Journal of applied microbiology. 107 (3), pp. 1031-41.

Lunden, T. et al. (1998): „Influence of oxytetracycline and oxolinic acid on the immune response of rainbow trout (Oncorhynchus mykiss) “. In: Fish and Shellfish Immunology. 8 (3), pp. 217-230.

Lunden, Tuula et al. (1999): „Effect of florfenicol on the immune response of rainbow trout (Oncorhynchus mykiss)". In: Veterinary immunology and immunopathology. 67 (4), pp. 317-325.

Lunden, Tuula; Bylund, Göran (2002): „Effect of sulphadiazine and trimethoprim on the immune response of rainbow trout (Oncorhynchus mykiss).“. In: Veterinary immunology and immunopathology. 85 (1-2), pp. 99-108.

Maenner, K; Vahjen, W; Simon, O (2011): „Studies on the effects of essential-oil-based feed additives on performance, ileal nutrient digestibility, and selected bacterial groups in the gastrointestinal tract of piglets.". In: Journal of animal science. 89 (7), pp. 2106-12.

Magnadottir, Bergljot (2010): „Immunological control of fish diseases.“. In: Marine biotechnology (New York, N.Y.). 12 (4), pp. 361-79.

Mahmoud, Barakat S.M et al. (2004): „Bacterial microflora of carp (Cyprinus carpio) and its shelf-life extension by essential oil compounds“. In: Food Microbiology. 21 (6), pp. 657-666.

Martínez, José L (2008): "Antibiotics and antibiotic resistance genes in natural environments.“. In: Science (New York, N.Y.). 321 (5887), pp. 365-7.

Martinsen, B; Horsberg, T E (1995): „Comparative single-dose pharmacokinetics of four quinolones, oxolinic acid, flumequine, sarafloxacin, and enrofloxacin, in Atlantic salmon (Salmo salar) held in seawater at 10 degrees C.". In: Antimicrobial agents and chemotherapy. 39 (5), pp. 1059-64. 
Mastromatteo, Marianna et al. (2010): „Shelf life of ready to use peeled shrimps as affected by thymol essential oil and modified atmosphere packaging.“. In: International journal of food microbiology. Elsevier B.V. 144 (2), pp. 250-6.

Mathur, M D; Vidhani, S; Mehndiratta, P L (2003): „Bacteriophage therapy: an alternative to conventional antibiotics.". In: The Journal of the Association of Physicians of India. 51 (June), pp. 593-6.

Mcintosh, F M et al. (2003): „Effects of Essential Oils on Ruminal Microorganisms and Their Protein Metabolism“. In: Society. 69 (8), pp. 5011-5014.

Mejlholm, O; Dalgaard, P (2002): „Antimicrobial effect of essential oils on the seafood spoilage micro-organism Photobacterium phosphoreum in liquid media and $₫$ sh products“. In: Letters in Applied Microbiology. pp. 27-31.

Merrifield, Daniel L. et al. (2010): "The current status and future focus of probiotic and prebiotic applications for salmonids". In: Aquaculture. Elsevier B.V. 302 (1-2), pp. $1-18$.

Miranda, C , Rojas R. (2007): " Occurrence of florfenicol resistance in bacteria associated with two Chilean salmon farms with different history of antibacterial usage ". In: Aquaculture 266 39-46

Miranda, C , Zemelman R. (2002): „Bacterial resistance to oxytetracycline in Chilean salmon farming". In: Aquaculture. 212 (1-4), pp. 31-47.

Miranda, Claudio D et al. (2003): „Diversity of Tetracycline Resistance Genes in Bacteria from Chilean Salmon Farms“. In: Society. 47 (3), pp. 883-888.

Moriarty, D J W (1998): „Control of luminous Vibrio species in penaeid aquaculture ponds“. In: Aquaculture. 164 (1-4), pp. 351-358.

Morohoshi, T et al. (2004): "Identification of quorum-sensing signal molecules and the LuxRI homologs in fish pathogen Edwardsiella tarda.“. In: Biosci Bioeng. 98 (4), pp. 274-276.

Muhl, a; Liebert, F (2007): „Growth and parameters of microflora in intestinal and faecal samples of piglets due to application of a phytogenic feed additive.“. In: Journal of animal physiology and animal nutrition. 91 (9-10), pp. 411-8.

Musthafa, K Syed et al. (2011): „Antipathogenic potential of marine Bacillus sp. SS4 on Nacyl-homoserine-lactone-mediated virulence factors production in Pseudomonas aeruginosa (PAO1)“. In: Journal of Biosciences. 36 (1), pp. 55-67.

Nagegowda, Dinesh a (2010): „Plant volatile terpenoid metabolism: biosynthetic genes, transcriptional regulation and subcellular compartmentation.". In: FEBS letters. Federation of European Biochemical Societies 584 (14), pp. 2965-73.

Nakai, T et al. (1999): „Protective effects of bacteriophage on experimental Lactococcus garvieae infection in yellowtail.“. In: Diseases of aquatic organisms. Faculty of Applied Biological Science, Hiroshima University, Higashihiroshima, Japan. nakaitt@ipc.hiroshima-u.ac.jp 37 (1), pp.33-41.

Nakai, Toshihiro; Park, Se Chang (2002): „Bacteriophage therapy of infectious diseases in aquaculture.". In: Research in microbiology. 153 (1), pp. 13-8.

Nakajima, T. et al. (1983): "Transmission of R plasmids in Vibrio anguillarum to Vibrio cholera“. In: Microbiology and Immunology. 27 , pp. 195-198.

Nakayama, T; Lu, H; Nomura, N (2009): „Inhibitory effects of Bacillus probionts on growth and toxin production of Vibrio harveyi pathogens of shrimp.". In: Letters in applied microbiology. 49 (6), pp. 679-84. 
Natrah, F M I; Defoirdt, Tom; et al. (2011): „Disruption of bacterial cell-to-cell communication by marine organisms and its relevance to aquaculture.". In: Marine biotechnology (New York, N.Y.). 13 (2), pp. 109-26.

Natrah, F M I; Ruwandeepika, H a Darshanee; et al. (2011): „Regulation of virulence factors by quorum sensing in Vibrio harveyi.". In: Veterinary microbiology. Elsevier B.V.

Navarrete, Paola et al. (2010): „Effect of Thymus vulgaris essential oil on intestinal bacterial microbiota of rainbow trout, Oncorhynchus mykiss (Walbaum) and bacterial isolates“. In: Aquaculture Research. pp. 667-678.

Navarrete, Paola et al. (o. J.): "Oxytetracycline treatment reduces bacterial diversity of intestinal microbiota of Atlantic salmon (Salmo salar )“. In:

Nayak, S K (2010): „Probiotics and immunity: a fish perspective.“. In: Fish \& shellfish immunology. Elsevier Ltd 29 (1), pp. 2-14.

Newaj-Fyzul, a et al. (2007): „Bacillus subtilis AB1 controls Aeromonas infection in rainbow trout (Oncorhynchus mykiss, Walbaum).“. In: Journal of applied microbiology. 103 (5), pp. 1699-706.

Nhan, D T et al. (2010): „Quorum quenching bacteria protect Macrobrachium rosenbergii larvae from Vibrio harveyi infection.". In: Journal of applied microbiology. 109 (3), pp. 1007-16.

Ninawe, A S; Selvin, Joseph (2009): „Probiotics in shrimp aquaculture: Avenues and challenges". In: Critical Reviews in Microbiology. Informa Healthcare 35 (1), pp. $43-$ 66.

Ochoa-Solano, Leonel; Olmos-Soto, Jorge (2006): „The functional property of Bacillus for shrimp feeds.“. In: Food microbiology. 23 (6), pp. 519-25.

Olmos, Jorge et al. (2011): „Functional Feed Assessment on Litopenaeus vannamei Using $100 \%$ Fish Meal Replacement by Soybean Meal, High Levels of Complex Carbohydrates and Bacillus Probiotic Strains.“. In: Marine drugs. 9 (6), pp. 1119-32.

Ortuño, J. Esteban, M.A.; Meseguer, J. (2001): „Effects of short-term crowding stress on the gilthead seabream (Sparus aurata L.) innate immune response“. In: Fish and Shellfish Immunology. 11 (2), pp. 187-197.

Park, S C et al. (2000): „Isolation of bacteriophages specific to a fish pathogen, Pseudomonas plecoglossicida, as a candidate for disease control.“. In: Applied and environmental microbiology. 66 (4), pp. 1416-22.

Park, Se Chang; Nakai, Toshihiro (2003): „Bacteriophage control of Pseudomonas plecoglossicida infection in ayu Plecoglossus altivelis“. In: Diseases Of Aquatic Organisms. 53 , pp. 33-39.

Pérez-Conesa, D et al. (2011): „Inactivation of Listeria monocytogenes and Escherichia coli O157:H7 biofilms by micelle-encapsulated eugenol and carvacrol.“. In: Journal Of Food Protection. 74 (1), pp. 55-62.

Pérez-Sánchez, T et al. (2011): „Identification and characterization of lactic acid bacteria isolated from rainbow trout, Oncorhynchus mykiss (Walbaum), with inhibitory activity against Lactococcus garvieae.“. In: Journal of fish diseases. 34 (7), pp. 499507.

Pichersky, E; Noel, J; Dudareva, N (2006): „Biosynthesis of plant volatiles: Nature's Diversity and ingenuity“. In: Science. 10 , pp. 808-811. 
Pickering, A. D.; Pottinger, T.G. (1989): „Stress responses and disease resistance in salmonid fish: Effects of chronic elevation of plasma cortisol“. In: Fish physiology and biochemistry. 7 (1-4), pp. 253-258.

Piva, a et al. (2007): „Lipid microencapsulation allows slow release of organic acids and natural identical flavors along the swine intestine.". In: Journal of animal science. 85 (2), pp. 486-93.

Planas, M et al. (2006): „Probiotic effect in vivo of Roseobacter strain 27-4 against Vibrio (Listonella) anguillarum infections in turbot (Scophthalmus maximus L.) larvae“. In: Aquaculture. 255 (1-4), pp. 323-333.

Ponce, a.G. et al. (2003): "Antimicrobial activity of essential oils on the native microflora of organic Swiss chard“. In: LWT - Food Science and Technology. 36 (7), pp. 679-684.

Pouliquen, H et al. (2007): "Comparative hydrolysis and photolysis of four antibacterial agents (oxytetracycline oxolinic acid, flumequine and florfenicol) in deionised water, freshwater and seawater under abiotic conditions“. In: Aquaculture. 262 (1), pp. 23-28.

Prado, Susana; Romalde, Jesús L; Barja, Juan L (2010): „Review of probiotics for use in bivalve hatcheries.". In: Veterinary microbiology. 145 (3-4), pp. 187-97.

Preetha, R et al. (2007): „Optimization of carbon and nitrogen sources and growth factors for the production of an aquaculture probiotic (Pseudomonas MCCB 103) using response surface methodology.". In: Journal of applied microbiology. 102 (4), pp. 1043-51.

Pyrgotou, Nikoletta et al. (2010): "Quality assessment of salted, modified atmosphere packaged rainbow trout under treatment with oregano essential oil.". In: Journal of food science. 75 (7), pp. M406-11.

Rali, Topul; Wossa, Stewart W; Leach, David N (2007): „Comparative chemical analysis of the essential oil constituents in the bark, heartwood and fruits of Cryptocarya massoy (Oken) Kosterm. (Lauraceae) from Papua New Guinea.“. In: Molecules Basel Switzerland. 12 (2), pp. 149-154.

Randrianarivelo, R et al. (2010): „Novel alternative to antibiotics in shrimp hatchery: effects of the essential oil of Cinnamosma fragrans on survival and bacterial concentration of Penaeus monodon larvae.". In: Journal of applied microbiology. 109 (2), pp. $642-$ 50.

Rasch, M et al. (2007): „Quorum sensing signals are produced by Aeromonas salmonicida and quorum sensing inhibitors can reduce production of a potential virulence factor". In: Diseases of Aquatic Organisms. 78 (2), pp. 105-113.

Rawls, John F; Samuel, Buck S; Gordon, Jeffrey I (2004): „Gnotobiotic zebrafish reveal evolutionarily conserved responses to the gut microbiota.". In: Proceedings of the National Academy of Sciences of the United States of America. 101 (13), pp. 4596601.

Rawn, Dorothea F. K. et al. (2009): "Analysis of fin and non-fin fish products for azamethiphos and dichlorvos residues from the Canadian retail market". In: International Journal of Food Science \& Technology. 44 (8), pp. 1510-1516.

Reid, Gregor et al. (2003): „Potential Uses of Probiotics in Clinical Practice“. In: Society. 16 (4), pp. 658-672.

Reyes-Becerril, Martha et al. (2008): „Oral delivery of live yeast Debaryomyces hansenii modulates the main innate immune parameters and the expression of immune- 
relevant genes in the gilthead seabream (Sparus aurata L.).“. In: Fish \& shellfish immunology. 25 (6), pp. 731-9.

Rijkers, G.T. Oosterom, R. Van; Muiswinkel, W.B. Van (1981): „The immune system of cyprinid fish. Oxytetracycline and the regulation of humoral immunity in carp (Cyprinus carpio)“. In: Veterinary immunology and immunopathology. 2 (3), pp. 281-290.

Ringø, Einar et al. (2004): „Damaging effect of the fish pathogen Aeromonas salmonicida ssp. salmonicida on intestinal enterocytes of Atlantic salmon (Salmo salar L.).“. In: Cell and tissue research. 318 (2), pp. 305-11.

Romero, Jaime; Navarrete, Paola (2006): „16S rDNA-based analysis of dominant bacterial populations associated with early life stages of coho salmon (Oncorhynchus kisutch).“. In: Microbial ecology. 51 (4), pp. 422-30.

Ruwandeepika, H A Darshanee et al. (2011): „Quorum sensing regulation of virulence gene expression in Vibrio harveyi in vitro and in vivo during infection of gnotobiotic brine shrimp larvae“. In: Environmental Microbiology Reports. Blackwell Publishing Ltd p. no-no.

Saglam, Naim; Yonar, M Enis (2009): „Effects of sulfamerazine on selected haematological and immunological parameters in rainbow trout (Onchorhynchus mykiss , Walbaum, 1792)“. In: Aquaculture Research. 40 (4), pp. 395-404.

Salinas, Irene et al. (2005): „Dietary administration of Lactobacillus delbrüeckii and Bacillus subtilis, single or combined, on gilthead seabream cellular innate immune responses.“. In: Fish \& shellfish immunology. 19 (1), pp. 67-77.

Samuelsen, O (2006): „Pharmacokinetics of quinolones in fish: A review“. In: Aquaculture. 255 (1-4), pp. 55-75.

Samuelsen, Ole B. Torsvik, V.; Ervik, A. (1992): „Long-range changes in oxytetracycline concentration and bacterial resistance towards oxytetracycline in a fish farm sediment after medication“. In: Science of the Total Environment. 114 , pp. 25-36.

Sarter, Samira et al. (2011): „Antimicrobial Effects of Essential Oils of Cinnamosma fragrans on the Bacterial Communities in the Rearing Water of Penaeus monodon Larvae“. In: Vector-Borne and Zoonotic Diseases. Mary Ann Liebert, Inc., publishers 11 (4), pp. 433-437.

Schnabel, E L; Jones, a L (1999): „Distribution of tetracycline resistance genes and transposons among phylloplane bacteria in Michigan apple orchards.“. In: Applied and environmental microbiology. 65 (11), pp. 4898-907.

Schulze, a et al. (2006): „Bacterial diversity in a marine hatchery: Balance between pathogenic and potentially probiotic bacterial strains“. In: Aquaculture. 256 (1-4), pp. 50-73.

Seyfried, Erin E et al. (2010): „Occurrence of tetracycline resistance genes in aquaculture facilities with varying use of oxytetracycline.". In: Microbial ecology. 59 (4), pp. 799-807.

Shekarforoush, S et al. (2007): „Effects of storage temperatures and essential oils of oregano and nutmeg on the growth and survival of Escherichia coli O157:H7 in barbecued chicken used in Iran“. In: Food Control. 18 (11), pp. 1428-1433.

Shivu, Mockshanath M et al. (2007): „Molecular characterization of Vibrio harveyi bacteriophages isolated from aquaculture environments along the coast of India.". In: Environmental microbiology. 9 (2), pp. 322-31. 
Smith, Peter; Samuelsen, Ole B (1996): „Estimates of the significance of out-washing of oxytetracycline from sediments under Atlantic salmon sea-cages“. In: Aquaculture. 144 (1-3), pp. 17-26.

Stenholm, Anne Rønnest; Dalsgaard, Inger; Middelboe, Mathias (2008): „Isolation and characterization of bacteriophages infecting the fish pathogen Flavobacterium psychrophilum. “. In: Applied and environmental microbiology. 74 (13), pp. 4070-8.

Stolte, Ellen H et al. (2009): „The immune response differentially regulates Hsp70 and glucocorticoid receptor expression in vitro and in vivo in common carp (Cyprinus carpio L.).“. In: Fish \& shellfish immunology. Elsevier Ltd 27 (1), pp. 9-16.

Stroh, J et al. (1998): „Evaluation of the acute toxicity to juvenile Pacific coho salmon and rainbow trout of some plant essential oils, a formulated product, and the carrier.". In: Bulletin of environmental contamination and toxicology. 60 (6), pp. 923-30.

Ström-Bestor, M; Wiklund, T (2011): „Inhibitory activity of Pseudomonas sp. on Flavobacterium psychrophilum, in vitro.“. In: Journal of fish diseases. 34 (4), pp. 255-64.

Sun, Yun-Zhang et al. (2010): „Probiotic applications of two dominant gut Bacillus strains with antagonistic activity improved the growth performance and immune responses of grouper Epinephelus coioides.“. In: Fish \& shellfish immunology. Elsevier Ltd 29 (5), pp. 803-9.

Tafalla, C. et al. (2002): „In vivo and in vitro effect of oxytetracycline treatment on the immune response of turbot, Scophthalmus maximus (L.)“. In: Journal of Fish Diseases. 22 (4), pp. 271-276.

Tamminen, Manu et al. (2011): „Tetracycline resistance genes persist at aquaculture farms in the absence of selection pressure.“. In: Environmental science \& technology. 45 (2), pp. 386-91.

Teasdale, Margaret E et al. (2009): „Secondary metabolites produced by the marine bacterium Halobacillus salinus that inhibit quorum sensing-controlled phenotypes in gram-negative bacteria.“. In: Applied and environmental microbiology. 75 (3), pp. 567-72.

Thompson, J et al. (2010): „An in vitro and in vivo assessment of the potential of Vibrio spp. as probiotics for the Pacific white shrimp, Litopenaeus vannamei.“. In: Journal of applied microbiology. 109 (4), pp. 1177-87.

Tinh, Nguyen Thi Ngoc et al. (2007): „N-acyl homoserine lactone-degrading microbial enrichment cultures isolated from Penaeus vannamei shrimp gut and their probiotic properties in Brachionus plicatilis cultures.“. In: FEMS microbiology ecology. 62 (1), pp. 45-53.

Tinh, Nguyen Thi Ngoc et al. (2008): "A review of the functionality of probiotics in the larviculture food chain.“. In: Marine biotechnology (New York, N.Y.). 10 (1), pp. 112.

Tovar-Ramírez, D. et al. (2010): „Dietary probiotic live yeast modulates antioxidant enzyme activities and gene expression of sea bass (Dicentrarchus labrax) larvae“. In: Aquaculture. Elsevier B.V. 300 (1-4), pp. 142-147.

Ultee, A; Bennik, M H J; Moezelaar, R (2002): „The Phenolic Hydroxyl Group of Carvacrol Is Essential for Action against the Food-Borne Pathogen Bacillus cereus“. In: Society. 68 (4), pp. 1561-1568. 
Van Hai, Ngo; Buller, Nicky; Fotedar, Ravi (2009): „The use of customised probiotics in the cultivation of western king prawns (Penaeus latisulcatus Kishinouye, 1896).“. In: Fish \& shellfish immunology. Elsevier Ltd 27 (2), pp. 100-4.

Van Vuuren, Sandy F et al. (2010): „Encapsulation of essential oils within a polymeric liposomal formulation for enhancement of antimicrobial efficacy.". In: Natural product communications. 5 (9), pp. 1401-1408.

Vaseeharan, B; Ramasamy, P (2003): „Control of pathogenic Vibrio spp. by Bacillus subtilis BT23, a possible probiotic treatment for black tiger shrimp Penaeus monodon.". In: Letters in applied microbiology. 36 (2), pp. 83-7.

Vazquez, J; Gonzalez, M; Murado, M (2005): „Effects of lactic acid bacteria cultures on pathogenic microbiota from fish“. In: Aquaculture. 245 (1-4), pp. 149-161.

Verner-Jeffreys, David W. et al. (2007): „Furunculosis in Atlantic salmon (Salmo salar L.) is not readily controllable by bacteriophage therapy“. In: Aquaculture. 270 (1-4), pp. 475-484.

Verschuere, L et al. (2000): „Probiotic bacteria as biological control agents in aquaculture.". In: Microbiology and molecular biology reviews : MMBR. 64 (4), pp. 655-71.

Villamil, L et al. (2002): „Evaluation of Immunomodulatory Effects of Lactic Acid Bacteria in Turbot ( Scophthalmus maximus )“. In: Society. 9 (6), pp. 1318-1323.

Vine, Niall G; Leukes, Winston D; Kaiser, Horst (2006): „Probiotics in marine larviculture.“. In: FEMS microbiology reviews. 30 (3), pp. 404-27.

Vinod, M et al. (2006): „Isolation of Vibrio harveyi bacteriophage with a potential for biocontrol of luminous vibriosis in hatchery environments“. In: Aquaculture. 255 (1-4), pp. 117-124.

Walakira, J K et al. (2008): „Identification and characterization of bacteriophages specific to the catfish pathogen, Edwardsiella ictaluri.“. In: Journal of applied microbiology. 105 (6), pp. 2133-42.

Wang, Q et al. (2009): „In vitro evaluation of the activity of microencapsulated carvacrol against Escherichia coli with K88 pili.“. In: Journal of applied microbiology. 107 (6), pp. 1781-8.

Windisch, W et al. (2008): „Use of phytogenic products as feed additives for swine and poultry.". In: Journal of animal science. 86 (14 Suppl), pp. E140-8.

Wishkovsky, A. Roberson, B.; Hetrick, F. M. (1987): „In vitro suppression of the phagocytic response of fish macrophages by tetracyclines“. In: Journal of fish biology. 31 , pp. 61-65.

Yang, W Z et al. (2007): „Effects of garlic and juniper berry essential oils on ruminal fermentation and on the site and extent of digestion in lactating cows.". In: Journal of dairy science. 90 (12), pp. 5671-81.

Yeh, Ruo-Yun et al. (2009): „Evaluation of the antibacterial activity of leaf and twig extracts of stout camphor tree, Cinnamomum kanehirae, and the effects on immunity and disease resistance of white shrimp, Litopenaeus vannamei.“. In: Fish \& shellfish immunology. 27 (1), pp. 26-32.

You, JianLan et al. (2007): „Inhibition of Vibrio biofilm formation by a marine actinomycete strain A66.“. In: Applied microbiology and biotechnology. 76 (5), pp. 1137-44.

Zheng, Z.L. et al. (2009): „Evaluation of oregano essential oil (Origanum heracleoticum L.) on growth, antioxidant effect and resistance against Aeromonas hydrophila in 
channel catfish (Ictalurus punctatus)“. In: Aquaculture. Elsevier B.V. 292 (3-4), pp. 214-218.

Zhou, X; Wang, Y; Li, W (2009): „Effect of probiotic on larvae shrimp (Penaeus vannamei) based on water quality, survival rate and digestive enzyme activities". In: Aquaculture. Elsevier B.V. 287 (3-4), pp. 349-353. 


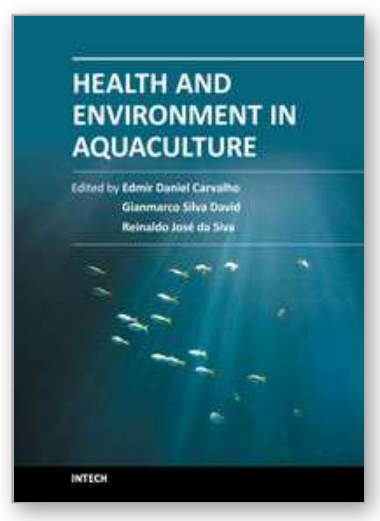

\author{
Health and Environment in Aquaculture \\ Edited by Dr. Edmir Carvalho
}

ISBN 978-953-51-0497-1

Hard cover, 414 pages

Publisher InTech

Published online 11, April, 2012

Published in print edition April, 2012

Aquaculture has been expanding in a fast rate, and further development should rely on the assimilation of scientific knowledge of diverse areas such as molecular and cellular biology, and ecology. Understanding the relation between farmed species and their pathogens and parasites, and this relation to environment is a great challenge. Scientific community is involved in building a model for aquaculture that does not harm ecosystems and provides a reliable source of healthy seafood. This book features contributions from renowned international authors, presenting high quality scientific chapters addressing key issues for effective health management of cultured aquatic animals. Available for open internet access, this book is an effort to reach the broadest diffusion of knowledge useful for both academic and productive sector.

\title{
How to reference
}

In order to correctly reference this scholarly work, feel free to copy and paste the following:

Jaime Romero, Carmen Gloria Feijoo and Paola Navarrete (2012). Antibiotics in Aquaculture - Use, Abuse and Alternatives, Health and Environment in Aquaculture, Dr. Edmir Carvalho (Ed.), ISBN: 978-953-51-0497-1, InTech, Available from: http://www.intechopen.com/books/health-and-environment-in-aquaculture/antibioticsin-aquaculture-use-abuse-and-alternatives-

\section{INTECH}

open science | open minds

\section{InTech Europe}

University Campus STeP Ri

Slavka Krautzeka 83/A

51000 Rijeka, Croatia

Phone: +385 (51) 770447

Fax: +385 (51) 686166

www.intechopen.com

\section{InTech China}

Unit 405, Office Block, Hotel Equatorial Shanghai

No.65, Yan An Road (West), Shanghai, 200040, China 中国上海市延安西路65号上海国际贵都大饭店办公楼 405 单元

Phone: +86-21-62489820

Fax: +86-21-62489821 
(C) 2012 The Author(s). Licensee IntechOpen. This is an open access article distributed under the terms of the Creative Commons Attribution 3.0 License, which permits unrestricted use, distribution, and reproduction in any medium, provided the original work is properly cited. 